\title{
Spatial patterns, environmental correlates, and potential seasonal migration triangle of polar cod (Boreogadus saida) distribution in the Chukchi and Beaufort seas
}

\author{
Caitlin E. Forster ${ }^{1}\left[\right.$. Brenda L. Norcross ${ }^{1} \cdot$ Franz J. Mueter $^{1} \cdot$ Elizabeth A. Logerwell ${ }^{2} \cdot$ Andrew C. Seitz $^{1}$
}

Received: 2 April 2019 / Revised: 15 January 2020 / Accepted: 10 February 2020 / Published online: 21 April 2020

(c) This is a U.S. government work and not under copyright protection in the U.S.; foreign copyright protection may apply 2020

\begin{abstract}
Polar cod (Boreogadus saida) is a key forage fish in the Arctic marine ecosystem and provides an energetic link between lower and upper trophic levels. Despite its ecological importance, spatially explicit studies synthesizing polar cod distributions across research efforts have not previously been conducted in its Pacific range. We used spatial generalized additive models to map the distribution of polar cod by size class and relative to environmental variables. We compiled demersal trawl data from 21 cruises conducted during 2004-2017 in the Chukchi and Beaufort seas, and investigated size-specific patterns in distribution to infer movement ecology of polar cod as it develops from juvenile to adult life stages. High abundances of juvenile polar cod $(\leq 70 \mathrm{~mm})$ in the northeastern Chukchi Sea and western Beaufort Sea were separated from another region of high abundance in the eastern Beaufort Sea, near the US and Canadian border, suggesting possible population structure in the Pacific Arctic. Relating environmental correlates to polar cod abundance demonstrated that temperature and salinity were related to juvenile distribution patterns, while depth was the primary correlate of adult distribution. A comparison of seasonal 2017 abundances of polar cod in the southern Chukchi Sea found low demersal abundance in the spring when compared to the summer. Seasonal differences in polar cod abundance suggest that polar cod migration may follow a classical 'migration triangle' route between nursery grounds as juveniles, feeding grounds as subadults, and spawning grounds as adults, in relation to ice cover and seasonal production in the Chukchi Sea.
\end{abstract}

Keywords Polar cod $\cdot$ Pacific arctic $\cdot$ Chukchi sea $\cdot$ Beaufort sea $\cdot$ Harden jones migration triangle

This article belongs to the special issue on the "Arctic Gadids in a Changing Climate," coordinated by Franz Mueter, Haakon Hop, Benjamin Laurel, Caroline Bouchard, and Brenda Norcross.

Electronic supplementary material The online version of this article (https://doi.org/10.1007/s00300-020-02631-4) contains supplementary material, which is available to authorized users.

Caitlin E. Forster

ceforster@alaska.edu

1 College of Fisheries and Ocean Sciences, University of Alaska Fairbanks, Fairbanks, AK 99775, USA

2 Alaska Fisheries Science Center, National Marine Fisheries Service, National Oceanic and Atmospheric Administration, 7600 Sand Point Way NE, Seattle, WA 98115, USA

\section{Introduction}

Currently, understanding of the basic life history of many marine organisms in the Arctic, including polar cod (Boreogadus saida), is based on intermittent "snapshots" of species' presence, abundance, and distribution. While the distribution and movement of polar cod has been investigated in Atlantic Arctic regions such as the East Greenland shelf (Astthorsson 2015), and the Barents, Laptev, and East Siberian seas (Ponomarenko 1968; Lønne and Gulliksen 1989), a comprehensive study synthesizing multiple research efforts to describe the distribution of polar cod is yet to be completed for its range in the Chukchi and Beaufort seas (Mueter et al. 2016).

Polar cod is an abundant, circumpolar forage fish species and is a critical trophic link in the Arctic marine ecosystem (Lowry and Frost 1981; Mecklenburg et al. 2011; Hop and Gjosaeter 2013). This small-bodied species spawns under sea ice in the late fall and early winter and has buoyant eggs 
that float to the ice-water interface (Graham and Hop 1995; Bouchard and Fortier 2011). Its diet is composed primarily of zooplankton such as copepods, hyperiid amphipods, and euphausiids in the summer, open water season (Rand et al. 2013; Gray et al. 2016), and ice amphipods and Calanus copepods in the winter, ice-covered season (Kohlbach et al. 2017). In the Pacific Arctic, polar cod is found in high salinity and intermediate water temperatures of the Chukchi Sea shelf (Norcross et al. 2010; Logerwell et al. 2017; De Robertis et al. 2017b). In the Beaufort Sea, polar cod is ubiquitous, present at all depths both on the shelf and the extending seaward down the slope (Benoit et al. 2008; Geoffroy et al. 2011; Norcross et al. 2017).

Body size and ontogeny influence the ability of fishes to exploit available resources and may affect their distribution with respect to these resources. As fish size increases, individuals become stronger swimmers and can exploit larger and more energetically valuable prey (Werner and Hall 1974; Christensen 1996; Clark et al. 2005), while increasing gape size widens the size range of exploitable resources (Scharf et al. 2000; Gray et al. 2017). In the Chukchi and Beaufort seas, body size influences the composition of prey in polar cod diets (Walkusz et al. 2013; Gray et al. 2016). Smaller polar cod are restricted to consuming small-bodied prey (i.e., calanoid and cyclopoid copepods), while larger individuals can also consume large-bodied zooplankton (i.e., hyperiid amphipods and euphausiids) (Gray et al. 2016; Norcross et al. 2017). Therefore, as ontogenetic increases in body size also improve prey resource accessibility, polar cod distribution is likely impacted by size-specific resource distribution.

Differential distribution in fish size with respect to resources can influence species-level life history strategies, including both ontogenetic and seasonal migration patterns. In classic 'migration triangle' theory, species migrate from nursery grounds to feeding grounds and finally to spawning grounds throughout the course of a life cycle (Harden Jones 1968; Secor 2002). Many species in the North Pacific exhibit this life history strategy, including close relatives of polar cod, Pacific cod (Gadus macrocephalus), and walleye pollock (Gadus chalcogrammus) (Shimada and Kimura 1994; Kotwicki et al. 2005). Seasonal migrations are also common for fish species in the highly seasonal North Pacific ecosystem. Pacific herring (Clupea pallasii) and yellowfin sole (Limanda aspera), for example, exploit abundant food resources as they migrate between summer feeding grounds and offshore overwintering grounds (Nichol 1998; Tojo et al. 2007). Both the ontogenetic and seasonal migration patterns of polar cod in the Pacific Arctic are not well established and could be improved with additional sampling beyond the August and September open water sampling season.

Global attention has recently shifted to the Arctic, creating a unique opportunity for national and international fisheries management organizations to incorporate precautionary management strategies from the outset. In 2009 the North Pacific Fisheries Management Council (NPFMC) closed US Arctic waters to commercial fishing until sufficient information becomes available to sustainably manage a fishery (NPFMC 2009). Polar cod is listed as one of only two finfish species with commercial potential within the NPFMC Arctic Fisheries Management Plan, and any fishery development would require a review of the life history of the potential target species, as well as an evaluation of the impacts to essential fish habitat. While a number of recent pelagic and demersal trawl surveys conducted by both the National Marine Fisheries Service and academic researchers (Rand and Logerwell 2011; Norcross et al. 2013; De Robertis et al. 2017b) have described broad patterns in polar cod distribution and overall abundance (Logerwell et al. 2015), a study specifically investigating polar cod distribution patterns across multiple years and many cruises is yet to be completed. Accordingly, we generated a comprehensive understanding of polar cod distribution in the Chukchi and Beaufort seas, investigating patterns with respect to size class, environmental covariates, and seasonal data in the southern Chukchi Sea to inform a hypothesis about a polar cod migration triangle.

\section{Methods}

\section{Study region}

Within US waters, polar cod is abundant in the Chukchi and Beaufort seas, two waterbodies with differing physical and biological conditions. The Chukchi Sea has a wide and shallow shelf with average depths ranging from 40 to $60 \mathrm{~m}$. This sea benefits from an inflow from three primary water masses, nutrient poor Alaska Coastal Water (ACW), nutrient-rich Bering Shelf Water (BSW), and nutrient-rich Anadyr Water (AW) (Fig. 1; Weingartner 1997; Weingartner et al. 2013; Danielson et al. 2017b). There is considerable mixing between the BSW and AW, creating a water mass that has been termed Bering Chukchi Summer Water (BCSW) (Danielson et al. 2017b). The ACW, BSW, and AW originate in the Bering Sea and travel northward through Bering Strait, transporting nutrients and creating areas of high primary production and rich benthic habitats in portions of the Chukchi Sea (Dunton et al. 2005; Grebmeier et al. 2006). The high levels of Chukchi Sea shelf productivity are influenced to a greater extent by nutrient input from BCSW, than by ACW (Grebmeier et al. 1988). In contrast to the Chukchi Sea, the Beaufort Sea has a much narrower shelf with a slope that drops off steeply to the Arctic Basin. In addition to nutrient-rich waters flowing eastward from the Chukchi Sea, oceanographic processes in the Beaufort 
Fig. 1 Schematic of oceanic current flow in the Chukchi and Beaufort seas. After S. Danielson, personal communication

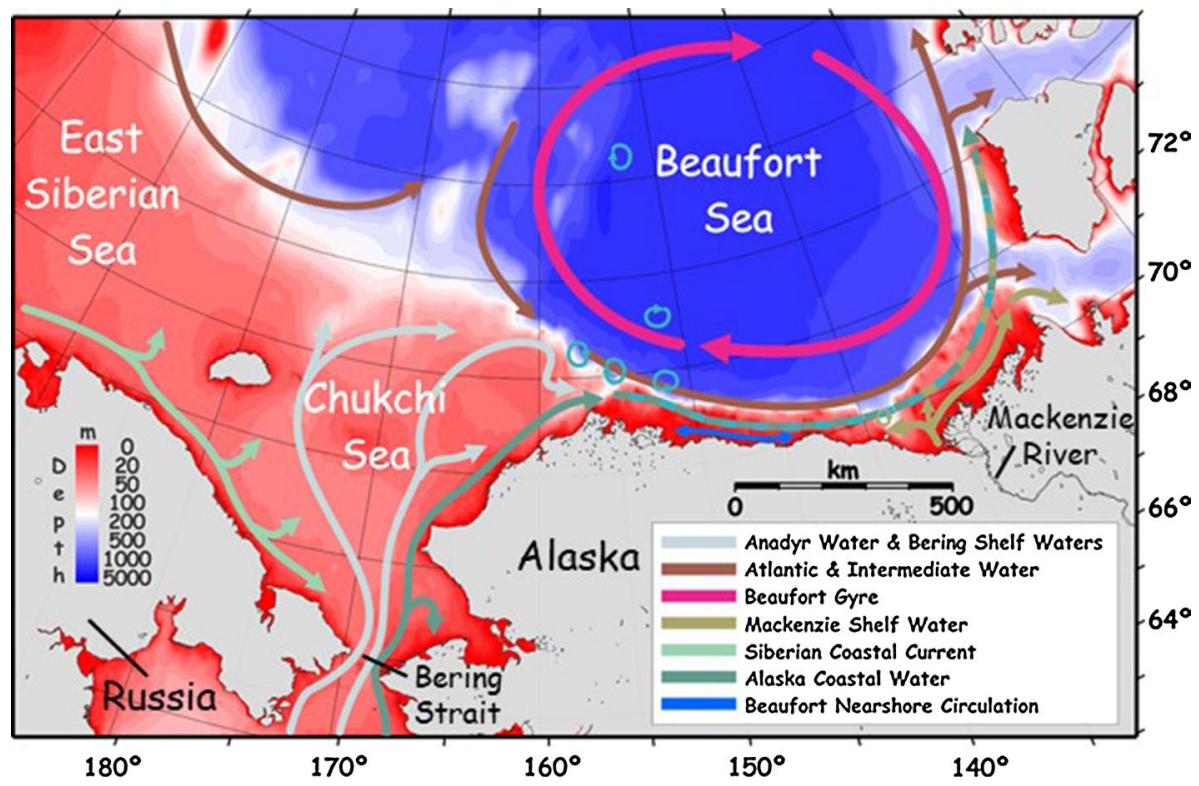

Sea are influenced by water from the Atlantic Ocean, the Beaufort Gyre, and freshwater input from the Mackenzie River (Carmack and Macdonald 2002). Water masses in the Beaufort Sea include a continuation of the eastward flowing ACW from the Chukchi Sea, Summer Shelf Water (SSW) influenced by both sub-Arctic and Arctic currents, and deep Atlantic Water (AtlW) transported west from the Atlantic Ocean (Carmack et al. 1989; Lansard et al. 2012; Norcross et al. 2018). Without nutrient subsidies from richer sub-Arctic waters, production in the Beaufort Sea is much lower than in the Chukchi Sea (Dunton et al. 2005). Regional differences in production create an unequal availability of resources between the Chukchi and Beaufort seas, which may drive both broad-scale patterns of polar cod distribution between the two seas, as well as more fine-scale patterns of polar cod distribution by size class in each respective sea.

\section{Data collection}

Data were compiled from 21 research surveys that were conducted during the open water season in the Chukchi and Beaufort seas beginning in 2004 and extending through 2017. Data were available from 16 cruises in the Chukchi Sea and five cruises in the Beaufort Sea (Table 1). In the Chukchi Sea, station locations ranged from approximately $170^{\circ} \mathrm{W}$ to Point Barrow, $156^{\circ} \mathrm{W}$, and from the Bering Strait, $66.4^{\circ} \mathrm{N}$, to approximately $73^{\circ} \mathrm{N}$. Because the Chukchi Sea is relatively shallow, sampled depths were commonly between 40 and $60 \mathrm{~m}$, with a maximum depth of $90 \mathrm{~m}$. Station locations in the Beaufort Sea extended along the Alaskan coast from Point Barrow and into Canadian waters past the Mackenzie River to $137^{\circ} \mathrm{W}$, and offshore to approximately $72^{\circ}$ $\mathrm{N}$ (Fig. 2). Sampled depths reached nearly $1000 \mathrm{~m}$ in the
Beaufort Sea. Cruises were divided into two seasons, spring and summer, based on temporal proximity of sampling to sea ice retreat and spring bloom conditions, which has a median date of approximately 20-21 June, based on data collected from 1997-2009 (Kahru et al. 2011). A cruise conducted from 9 to 29 June 2017 in the Chukchi Sea (ASGARD, Table 1), produced some of the earliest seasonal sampling events to ever take place in this region and was categorized as a spring season cruise because sampling occurred at the same time as the spring bloom (Danielson et al. 2017a). The remaining 20 cruises, conducted from 7 July to 10 October, occurred after the initial pulse of spring production from the spring bloom, and were thus categorized as summer season cruises. Because sampling in the spring occurred much earlier than during other cruises, data from this season were excluded from a spatial analysis of the summer distribution of polar cod. Further description of sensitivity analyses regarding seasonal divisions are discussed below.

All polar cod were captured in one of two configurations of a 3-m plumb staff beam trawl (PSBT), either standard (Gunderson and Ellis 1986) or modified with rollers (Abookire and Rose 2005), which were deployed for 1-10 min and towed at a speed over ground of 1.5-2.0 knots. A rigid $3.05 \mathrm{~m}$ beam held the net open for an effective swath of $2.26 \mathrm{~m}$; net mesh size was $7 \mathrm{~mm}$ in the body with a $4 \mathrm{~mm}$ codend liner. In a gear comparison study, neither catch per unit effort (CPUE) of all fishes nor size classes of polar cod were significantly different between these two gear types (Norcross et al. 2018), therefore, abundance data from both gear types were pooled for analysis. Fishing effort for each haul was defined as the total seafloor area swept by the net. Catches were standardized to an area of $1000 \mathrm{~m}^{2}$ (catch per unit effort or CPUE in no. of fish per $1000 \mathrm{~m}^{2}$ ). 
Table 1 Cruise information for all surveys used in this study listed by cruise designator, vessel used, year, beginning date of sampling, ending date of sampling, and number of hauls collected

\begin{tabular}{|c|c|c|c|c|c|c|}
\hline Region & Cruise designator & Vessel & Year & Begin date & End date & No. of hauls \\
\hline Chukchi & RUSALCA_2004 & R/V Professor Khromov & 2004 & 10-Aug & 22-Aug & 5 \\
\hline Chukchi & OD0710 & R/V Oscar Dyson & 2007 & 4-Sep & 15-Sep & 21 \\
\hline Chukchi & OS180 & T/S Oshoro-Maru IV & 2007 & 6-Aug & 10-Aug & 9 \\
\hline Chukchi & OS190 & T/S Oshoro-Maru IV & 2008 & 7-Jul & 13-Jul & 15 \\
\hline Chukchi & COMIDA_2009 & R/V Alpha Helix & 2009 & 27-Jul & 11-Aug & 30 \\
\hline Chukchi & RUSALCA_2009 & R/V Professor Khromov & 2009 & 4-Sep & 29-Sep & 7 \\
\hline Chukchi & WWW0902 & R/V Westward Wind & 2009 & 14-Aug & 29-Aug & 25 \\
\hline Chukchi & WWW0904 & $\mathrm{R} / \mathrm{V}$ Westward Wind & 2009 & 29-Sep & $10-$ Oct & 26 \\
\hline Chukchi & $\mathrm{AKCH} 10$ & R/V Norseman II & 2010 & 21-Aug & 4-Sep & 30 \\
\hline Chukchi & WWW1003 & R/V Westward Wind & 2010 & 1-Sep & 18-Sep & 40 \\
\hline Chukchi & AKCH11 & R/V Norseman II & 2011 & 4-Sep & 17-Sep & 28 \\
\hline Chukchi & Arctic EIS_2012 & F/V Alaska Knight & 2012 & 14-Aug & 18-Sep & 40 \\
\hline Chukchi & RUSALCA_2012 & R/V Professor Khromov & 2012 & 27-Aug & 16-Sep & 5 \\
\hline Chukchi & AMBON_2015 & R/V Norseman II & 2015 & 11-Aug & 3-Sep & 68 \\
\hline Chukchi & Arctic IES_2017 & R/V Ocean Starr & 2017 & 1-Aug & 28-Sep & 59 \\
\hline Chukchi & ASGARD_2017 & R/V Sikuliaq & 2017 & 9-Jun & 29-Jun & 8 \\
\hline Beaufort & BOEM_2011 & R/V Norseman II & 2011 & 15-Aug & 4-Sep & 81 \\
\hline Beaufort & TB_2013 & R/V Norseman II & 2013 & 12-Aug & 2-Sep & 90 \\
\hline Beaufort & ANIMIDA_2014 & R/V Norseman II & 2014 & 29-Jul & 10-Aug & 29 \\
\hline Beaufort & TB_2014 & R/V Norseman II & 2014 & 14-Aug & 2-Sep & 68 \\
\hline Beaufort & ANIMIDA_2015 & R/V Norseman II & 2015 & 31-Jul & 8-Aug & 18 \\
\hline & & & \multicolumn{3}{|c|}{ Total no. of hauls } & 697 \\
\hline
\end{tabular}

Due to difference in sampling seasons, ASGARD_2017 cruise excluded from spatial analysis

In addition, at each haul location a Seabird conductivitytemperature-depth (CTD) recorder was deployed from the vessel separately and used to measure depth (m), bottom water temperature $\left({ }^{\circ} \mathrm{C}\right)$, and bottom water salinity (PSU), hereafter referred to as depth, temperature, and salinity. Fish specimens were measured for total length.

\section{Data analysis}

Patterns in polar cod abundance and total length were plotted and inspected prior to statistical analysis. Length frequencies of 6519 and 2752 fish in the Chukchi and Beaufort seas, respectively, were plotted by $10 \mathrm{~mm}$ increments $(1-10 \mathrm{~mm}$, 11-20 mm, etc.) and examined to inform selection of size classes for analysis (Fig. 3). Visual inspection suggested the presence of three modes, therefore size classes were identified using an expectation-maximization (EM) algorithm to fit a mixture of three Gaussian distributions to the lengthfrequency data (Benaglia et al. 2009). Based on the results, abundances of polar cod were separated by total length into small $(\leq 70 \mathrm{~mm})$, medium $(71-130 \mathrm{~mm})$, and large $(>130 \mathrm{~mm})$ size classes. Size classes approximately correspond with age 0,1 , and $2+$ polar cod, respectively, based on previously published work (Helser et al. 2017). However, given considerable overlap in length-at-age distributions, the medium size class likely contains a mixture of age- 1 and age- 2 individuals.

Generalized additive modeling (GAM) was used to relate CPUE of polar cod to spatial and environmental predictor variables. A GAM is a regression technique that uses nonparametric smoothers to allow non-linear relationships between dependent and independent variables (Hastie and Tibshirani 1986; Wood 2006). The GAM approach was chosen to accommodate non-linear relationships between abundance and both spatial (latitude, longitude) and environmental (depth, temperature, salinity) predictors. All models were fit using the 'mgcv' package version 1.8-17 (Wood 2006) in R version 3.4.1 (R Core Team 2017). Analysis may be found in Online Resource 1.

To determine the most appropriate model framework for both the spatial and environmental GAM analyses, preliminary analyses and model diagnostics were conducted prior to selection of final models. Abundance of polar cod was non-normal, including a high proportion of zero-catch hauls, as well as a few hauls with very high abundance values. Exploratory analyses compared models using a Gaussian distribution with log-transformed polar cod CPUE and the identity link function, with negative binomial and tweedie 
Fig. 2 Catch per unit effort (CPUE, no. of fish per 1000 $\mathrm{m}^{2}$ ) of polar cod by haul in the Chukchi Sea (top panel) and Beaufort Sea (bottom panel). The + symbol denotes hauls where zero polar cod were caught. Colors correspond to separate cruises. Symbol size is proportional to CPUE. For details about each cruise, see Table 1

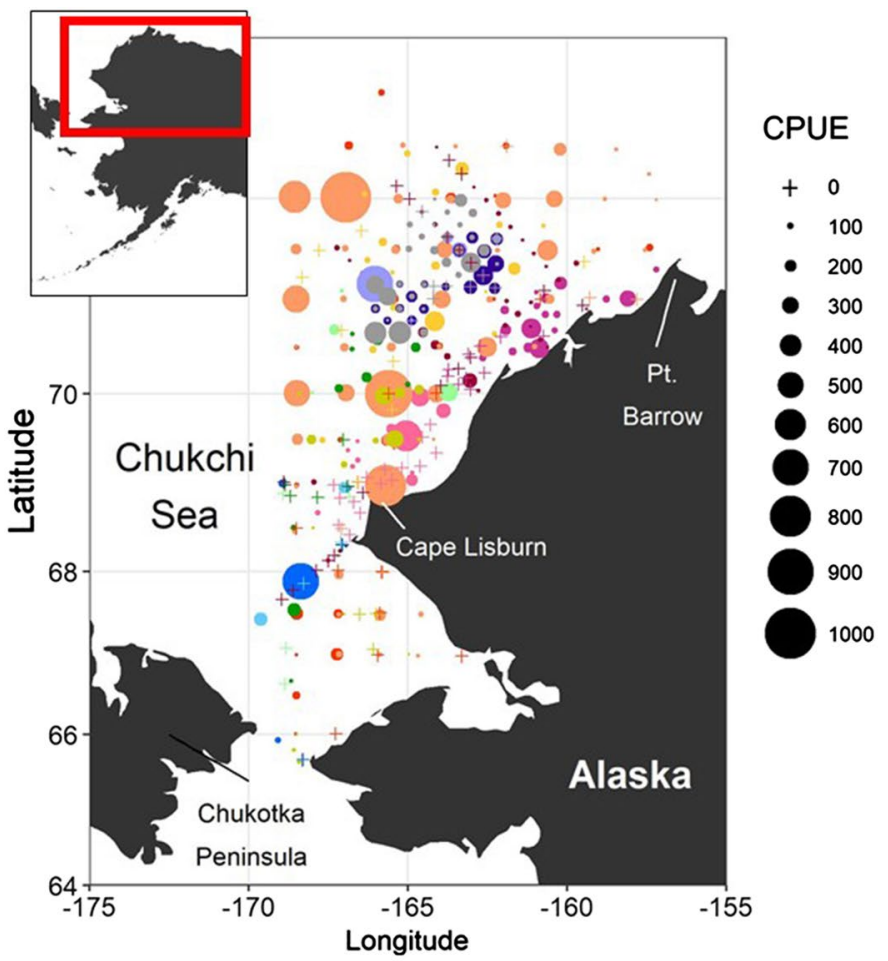

Cruise

- $\mathrm{AKCH} 10$

- $\mathrm{AKCH} 11$

- AMBON_2015

- Arctic Eis_2012

- Arctic IES_2017

- COMIDA_2009

- OD0710

OS180

- OS190

- RUSALCA_2004

- RUSALCA_2009

- RUSALCA_2012

- WWW0902

- WWW0904

- WWW1003

Cruise

- ANIMIDA_2014

ANIMIDA_2015

- BOEM_2011

- TB_2013

TB_2014 distributions using counts of polar cod and the log link function. The negative binomial distribution with a log link was selected as the top performing model based on residual diagnostics, deviance explained, and generalized cross validation scores. This model framework was thereafter used for all GAM analyses. The negative binomial distribution utilizes count data, and is commonly used for analyzing ecological data, as it can accommodate overdispersed observations, or observations with a high proportion of zeros (Zuur et al. 2007). Therefore, we used the count data with a log link and accounted for fishing effort by including the logarithm of area swept $\left(\mathrm{m}^{2}\right)$ as an offset in the model.

GAM analyses were conducted on cruises conducted in the summer season, defined as open water and more than 30 days after the start of the spring bloom. Two cruises, T/S Oshoro-Maru IV 2008 (Table 1) and WWW0904 2009 were conducted early and late in the summer season (July and October). To verify that it was appropriate to include these cruises in an analysis of polar cod summer distribution patterns, a sensitivity analysis both including and excluding these cruises was conducted. The results of all analyses were virtually identical; therefore, T/S Oshoro-Maru IV 2008 and WWW0904 2009 were included in summer season analyses. Due to considerable differences in oceanographic and bathymetric conditions and due to their spatial separation, analyses were conducted separately for the Chukchi and Beaufort seas.

To describe polar cod distribution patterns and the impact of environmental drivers on those patterns, two separate analyses were undertaken using GAM. The first analysis described the spatial distribution of polar cod abundance using latitude and longitude as covariates. Environmental conditions were strongly confounded with spatial location; for example, in the Beaufort Sea, depth increased with 
Fig. 3 Length-frequency distribution of polar cod captured in Chukchi Sea (blue) and Beaufort Sea (pink), weighted by station-specific catch per unit effort (CPUE, no. of fish per $1000 \mathrm{~m}^{2}$ ). Percent frequency is percent of total CPUE for that sea, and bars represent size class in between tick marks. Asterisks above a length bin indicate percentage $<0.1 \%$, color corresponds to sea

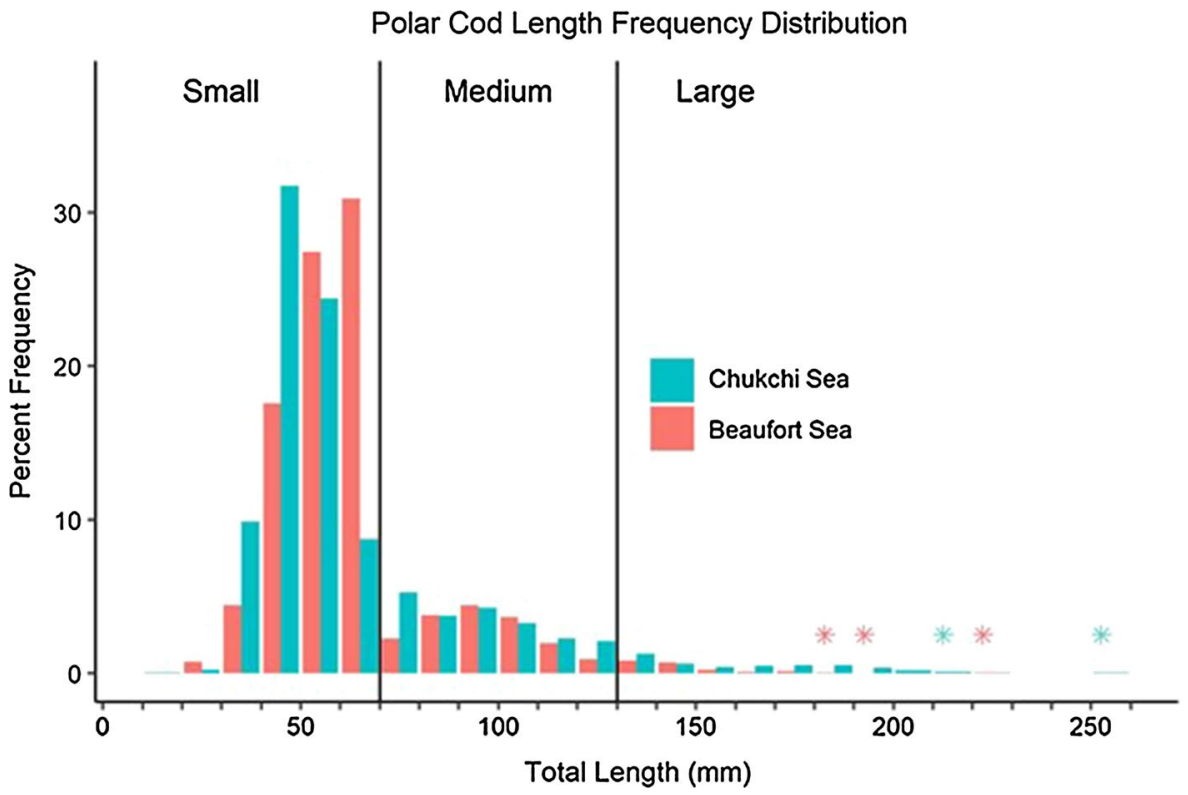

latitude as sampling moved both northerly and offshore. Thus, we modeled spatial patterns separately from assessing the effects of environmental covariates. We compared the predicted values of the spatial and environmental models at each station to examine to what extent environmental covariates were able to account for estimated spatial patterns in polar cod distribution. Results of this analysis may be found in Online Resource 2. Spatial and environmental analyses were conducted for each of the three length classes of polar cod in the Chukchi and Beaufort seas. The spatial model was fit as follows:

$\log ($ count of polar cod $) \sim s($ latitude, longitude $)+\log ($ area swept $)$,

where log denotes the natural logarithm and $s$ denotes a smooth function of latitude and longitude estimated using a thin-plate regression spline. The second analysis investigated the impact of environmental correlates by modeling polar cod abundance as a function of selected environmental covariates:

$$
\begin{aligned}
& \log (\text { count of polar cod }) \sim s_{1}(\text { depth }) \\
& +s_{2}(\text { temperature })+s_{3}(\text { salinity }) \\
& +\log (\text { area swept })
\end{aligned}
$$

where the $s_{i}$ are smooth functions of the respective covariates estimated using thin-plate regression splines. For the environmental analysis, a model selection approach was used to select a best-fitting model. To evaluate the effect of each environmental covariate on polar cod abundance, a suite of seven models was developed for each size class and in each sea, where every combination of environmental variables was considered. Within a size class and a sea, models were compared and the model with the lowest Akaike Information Criterion (AIC) was selected as the best performing model. Results from the best-fitting model for each size class were visually examined to describe the estimated relationships between polar cod abundance and the environmental predictors. When the best performing environmental model included both temperature and salinity, the temperature and salinity values were used to identify water masses and relate them to polar cod abundance. Literature values characterizing typical water mass temperature and salinity ranges in the Chukchi Sea (Danielson et al. 2017b) or Beaufort Sea (Norcross et al. 2018) were overlaid on relationships of polar cod abundance relative to those variables to determine patterns of polar cod abundance with respect to water mass.

Environmental model residuals suggested some degree of spatial autocorrelation among sites, where sites closer to each other were more similar than sites that were located farther apart. Both spatial and environmental models were tested for residual spatial autocorrelation by plotting the semivariance of model residuals as a function of distance between sampling points by year. Data for all length classes were combined to determine the spatial relationship between stations in each sea within a year. Comparison of AIC between the full model with spatial autocorrelation and the full model without spatial autocorrelation indicated slightly lower values in each sea (Chukchi Sea: $\Delta \mathrm{AIC}=2$; Beaufort Sea: $\Delta \mathrm{AIC}=10$ ) and thus a modest preference for the models that include a spatially autocorrelated error structure. Each environmental model, therefore, included an exponential decline in residual correlation with distance, as well as a nugget effect, conditioned on sampling year. Spatial correlation scale parameters (range and nugget) were estimated independently for each sea using the full model and were 
included in all subsequent models. Due to statistical programming constraints caused by the inclusion of a spatially autocorrelated error structure, the dispersion parameter of the negative binomial distribution was estimated independently using the full model and fixed for each sea. After the incorporation of a spatially correlated error structure in the environmental model, both the spatial models and environmental models met assumptions of independence.

The completion of the spring cruise in the Chukchi Sea in June 2017 provided a seasonal comparison of offshore polar cod abundances. As these data were collected in spring rather than summer, they were not included in the previously described spatial analysis. However, the spring abundance data were directly compared to abundance from a cruise conducted during August and September 2017 in the southern Chukchi Sea. The two research efforts used the same gear and sampled from the Bering Strait $\left(66.4^{\circ} \mathrm{N}\right)$ to Cape Lisburne $\left(69.1^{\circ} \mathrm{N}\right)$. Due to the small number of sample stations within the area of overlap (spring $n=9$, summer $n=14$ ), we were not able to develop a geostatistical model and instead compared abundance of polar cod between spring and summer using a non-parametric (rank-based) Wilcoxon two-sample test. The test assumes that sampling in each season resulted in independent random samples that were representative of the area of overlap. Several August hauls caught large numbers of fish $\leq 70 \mathrm{~mm}$, a size that was not observed in June. These small fish presumably consist of young-of-the-year fish that were too small to be retained by the beam trawl in June. Therefore, instead of statistically comparing overall seasonal abundances for all sizes of polar cod, we only applied to Wilcoxon two-sample test to compare seasonal abundances for fish $>70 \mathrm{~mm}$, i.e., those fish that were available to be caught by the gear in both spring and summer. Mean values of depth, temperature, and salinity for each season are reported; however, environmental data were not available for two stations sampled in August 2017.

\section{Results}

A total of 697 hauls from 21 cruises over 13 years were available for analysis (Table 1). The number of hauls conducted annually ranged from 5 to 88 in the Chukchi Sea and 18 to 97 in the Beaufort Sea. Sampling was conducted from 9 June to 10 October in the Chukchi Sea and from 29 July to 4 September in the Beaufort Sea. Bottom water in the Chukchi Sea ranged from -1.8 to $10.9{ }^{\circ} \mathrm{C}$, with salinities from 27.2 to 34.5 PSU. In comparison, conditions in the Beaufort Sea lacked the warmest and very coldest temperatures, with a range from -1.6 to $4.8^{\circ} \mathrm{C}$, and had salinities from 29.2 to $34.9 \mathrm{PSU}$.
When pooling data across all years, polar cod showed latitudinal patterns in abundance in the Chukchi Sea and a strong longitudinal gradient in the Beaufort Sea. Generally, abundance of polar cod in the Chukchi Sea showed a south to north gradient, with the highest abundance values north of Cape Lisburne (Fig. 2). In the Beaufort Sea, polar cod abundance showed a predominantly west to east gradient, with the highest abundance west of $150^{\circ} \mathrm{W}$ (Fig. 2). Length frequencies of the catches were similar across both study regions; polar cod ranged from 11 to $260 \mathrm{~mm}$ in the Chukchi Sea and from 21 to $230 \mathrm{~mm}$ in the Beaufort Sea (Fig. 3).

\section{Spatial analysis}

In the Chukchi Sea, GAM analysis of trawl catches revealed distinct patterns of polar cod distribution by size class. The small size class of polar cod was most abundant in the northern Chukchi Sea, north of approximately $68^{\circ} \mathrm{N}$ (Fig. 4), where the Bering Chukchi Summer Water mass is commonly present, while fewer small polar cod were found south of $68^{\circ} \mathrm{N}$. The distribution of the medium size class was different when compared to the distribution of the small size class and did not show the same region of abundance in the NE Chukchi Sea. Medium-sized polar cod were present across the entire Chukchi Sea shelf and showed pockets of high abundance in both nearshore and offshore regions. However, the regions of high abundance for the medium size class were not the same as the regions of high abundance for the small size class offshore at $169^{\circ} \mathrm{W}$ and north of $70^{\circ} \mathrm{N}$ (Fig. 4). Finally, the large size class of polar cod was less abundant in the nearshore region and more abundant beginning $\sim 80 \mathrm{~km}$ offshore and extending seaward, with an area of higher abundance south of Cape Lisburne (Fig. 4). Deviance explained for the small, medium, and large size class models was $24.4 \%, 20.2 \%$, and $57.5 \%$, respectively (Table 2 ).

Similar to the Chukchi Sea, the GAM spatial analysis in the Beaufort Sea also found distinct, size-based patterns of polar cod distribution. The small size class was distributed primarily along a west to east gradient, with an area of high abundance west of $150^{\circ} \mathrm{W}$, and another smaller area of abundance nearshore and east of $144^{\circ} \mathrm{W}$ (Fig. 5). There was also a nearshore to offshore gradient, where small polar cod were distributed close to shore; however, the western aggregation was dispersed across the width of the entire Beaufort Sea shelf (to $\sim 80 \mathrm{~km}$ ), more than the eastern aggregation that was generally distributed closer to shore (within $\sim 50 \mathrm{~km}$ ). Abundance of the medium size class showed a less extreme longitudinal gradient than the small size class, and while abundance was highest west of $150^{\circ} \mathrm{W}$, medium polar cod were diffuse across the entire Alaskan Beaufort Sea shelf. Unlike the small size class, medium-sized polar cod did not show a separate area of high abundance east of $144^{\circ} \mathrm{W}$. The large size class of 

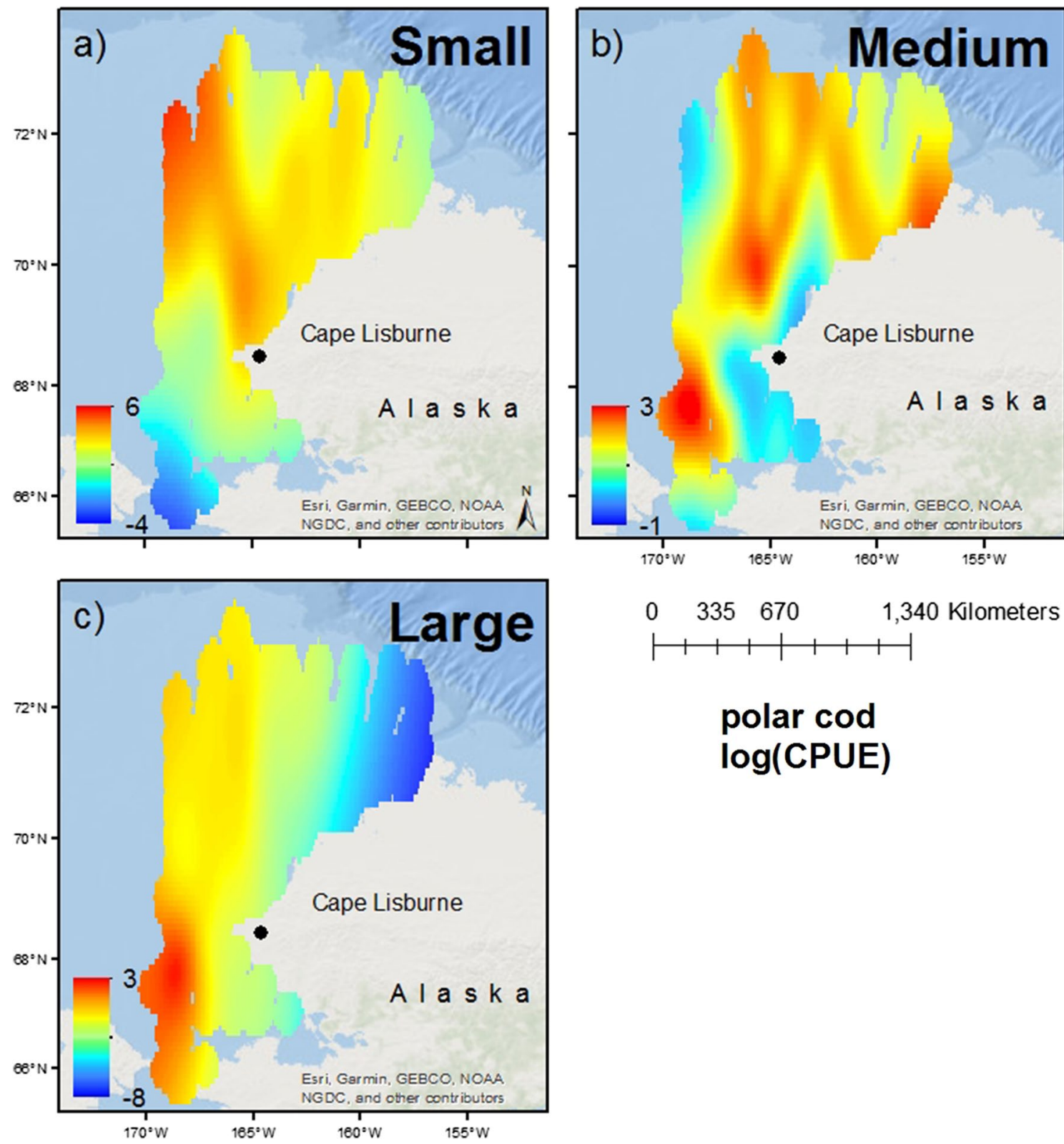

\section{polar cod $\log ($ CPUE)}

Fig. 4 Spatial distribution of polar cod catch per unit effort (CPUE, no. of fish per $\left.1000 \mathrm{~m}^{2}\right)$ in the Chukchi Sea for a small $(\leq 70 \mathrm{~mm})$, b medium $(71-130 \mathrm{~mm})$, and c large $(>130 \mathrm{~mm})$ size classes. Abun-

polar cod was distributed offshore, beyond $\sim 60 \mathrm{~km}$. The deviance explained for the small, medium, and large size class analysis was $62.7 \%, 22.9 \%$, and $21.7 \%$, respectively (Table 2).

\section{Environmental analysis}

In the Chukchi Sea, the influence of the environmental variables on polar cod abundance depended on size class. For the small size class of polar cod, the top performing model included both temperature and salinity (Table 3). A dances as predicted by generalized additive model (GAM) using a smooth function of latitude and longitude, shown on the log scale

dome-shaped curve described the relationship between polar cod abundance and temperature with a peak at $4-5{ }^{\circ} \mathrm{C}$, while abundances increased linearly with salinity to a maximum of 34.5 PSU (Fig. 6). For polar cod in the medium size class, the top performing model only included depth and abundance increased linearly with depth (Table 3, Fig. 6). The best-fitting model for the large size class of polar cod in the Chukchi Sea also only included depth as a covariate; there was a positive relationship between depth and abundance of large polar cod in the Chukchi Sea (Table 3, Fig. 6). 
Table 2 Results of generalized additive models (GAMs) for spatial distribution of polar cod, with latitude and longitude as explanatory variables (see Eq. 1)

\begin{tabular}{llllrlrl}
\hline Region & Size class & $\theta$ & edf & \multicolumn{1}{l}{$\chi^{2}$} & $p$ value & AIC & $\begin{array}{l}\text { Deviance } \\
\text { explained } \\
(\%)\end{array}$ \\
\hline Chukchi & Small & 0.19 & 19.5 & 99.3 & $<0.0001$ & 1928.0 & 24.4 \\
Chukchi & Medium & 0.40 & 26.6 & 67.0 & $<0.0001$ & 1642.0 & 20.2 \\
Chukchi & Large & 0.18 & 13.7 & 58.1 & $<0.0001$ & 426.9 & 57.5 \\
Beaufort & Small & 0.38 & 13.4 & 300.2 & $<0.0001$ & 1073.2 & 62.7 \\
Beaufort & Medium & 0.53 & 7.6 & 61.4 & $<0.0001$ & 1051.0 & 22.9 \\
Beaufort & Large & 0.19 & 3.0 & 23.1 & $<0.0001$ & 353.9 & 21.7 \\
\hline
\end{tabular}

Separate models developed in each sea and for each size class. $\theta$ parameter used for negative binomial parameterization, estimated degrees of freedom (edf), chi-square statistic, p-value denoting significance of latitude and longitude covariates, Akaike Information Criterion (AIC), and deviance explained
As in the Chukchi Sea, the relationships between environmental variables and abundance of polar cod in the Beaufort Sea were specific to size classes. The best-fitting model for the small size class in the Beaufort Sea included both temperature and salinity (Table 4). Abundance of small polar cod in the Beaufort Sea increased linearly to a maximum temperature of $4.8^{\circ} \mathrm{C}$, which was similar to the Chukchi Sea, and was highest at intermediate salinities; small polar cod were less abundant at the lowest $(<31$ PSU) and highest (>34 PSU) salinity values (Fig. 7). The top performing model for the medium size class in the Beaufort Sea included both depth and temperature (Table 4), unlike the analogous model in the Chukchi Sea, which only included depth. In the Beaufort Sea, abundance of medium polar cod increased with depth to approximately $300 \mathrm{~m}$ and then began to decline; medium polar cod abundance increased linearly with temperature (Fig. 7). As in the Chukchi Sea, the top performing model for the large size class included only depth as a covariate (Table 4). Notably, large polar cod abundance increased with depth in the Beaufort Sea to about $400 \mathrm{~m}$, but as depth surpassed $400 \mathrm{~m}$, abundance of polar cod decreased (Fig. 7). The shape of the relationship between depth and abundance was similar for both medium and large polar cod, but the medium size class was more abundant at shallow depths than the large size class of polar cod.

\section{Seasonal analysis}

Comparison of polar cod catches between spring and summer in the southern Chukchi Sea revealed striking differences in fish abundance. Overall mean abundance of polar cod was much lower in June 2017 compared to August 2017 (Table 5). During the spring, polar cod was scarce in our nets; only four individuals were captured at three sampling locations (Fig. 8). In contrast, polar cod abundance was higher at locations sampled in August 2017 (Table 5). There were summer hauls that captured high abundances of small-sized polar cod, including one station with an abundance of 832 fish per $1000 \mathrm{~m}^{2}$, with individuals ranging from 31 to $70 \mathrm{~mm}$ in length. Catch length-frequency composition in the summer contrasts with the polar cod caught in the spring, where only one fish $<70 \mathrm{~mm}$ was captured (Fig. 8). Polar cod 31 to $70 \mathrm{~mm}$ captured in August were likely young-of-the-year; these small fish were not available to the beam trawl in June due to both their pelagic distribution and small size before the summer growing season. Therefore, to verify that the observed seasonal differences in abundance were truly changes in abundance, and not the result of small fish growing in size and descending to the seafloor to become increasingly represented in the catch as the summer progressed, only spring and summer abundance of individuals $>70 \mathrm{~mm}$ were statistically compared. Seasonal differences in abundance were significant, using a Wilcoxon two-sample test, after the exclusion of small, highly abundant polar cod in August (Table 5, $p=0.02$ ).

\section{Discussion}

By visualizing the distribution patterns of small, medium, and large polar cod, understanding of ontogenetic shifts in distribution as well as possible migration patterns of this species in the Pacific Arctic has been improved. Furthermore, by relating patterns in distribution to environmental variables, we provide insight into potential mechanisms driving polar cod distribution. The importance of environmental covariates varies among the three size classes and suggests that the relative influence of external drivers on polar cod distribution influences life stages differently. A comparison of abundance between spring and summer in the southern Chukchi Sea revealed seasonal differences in polar 

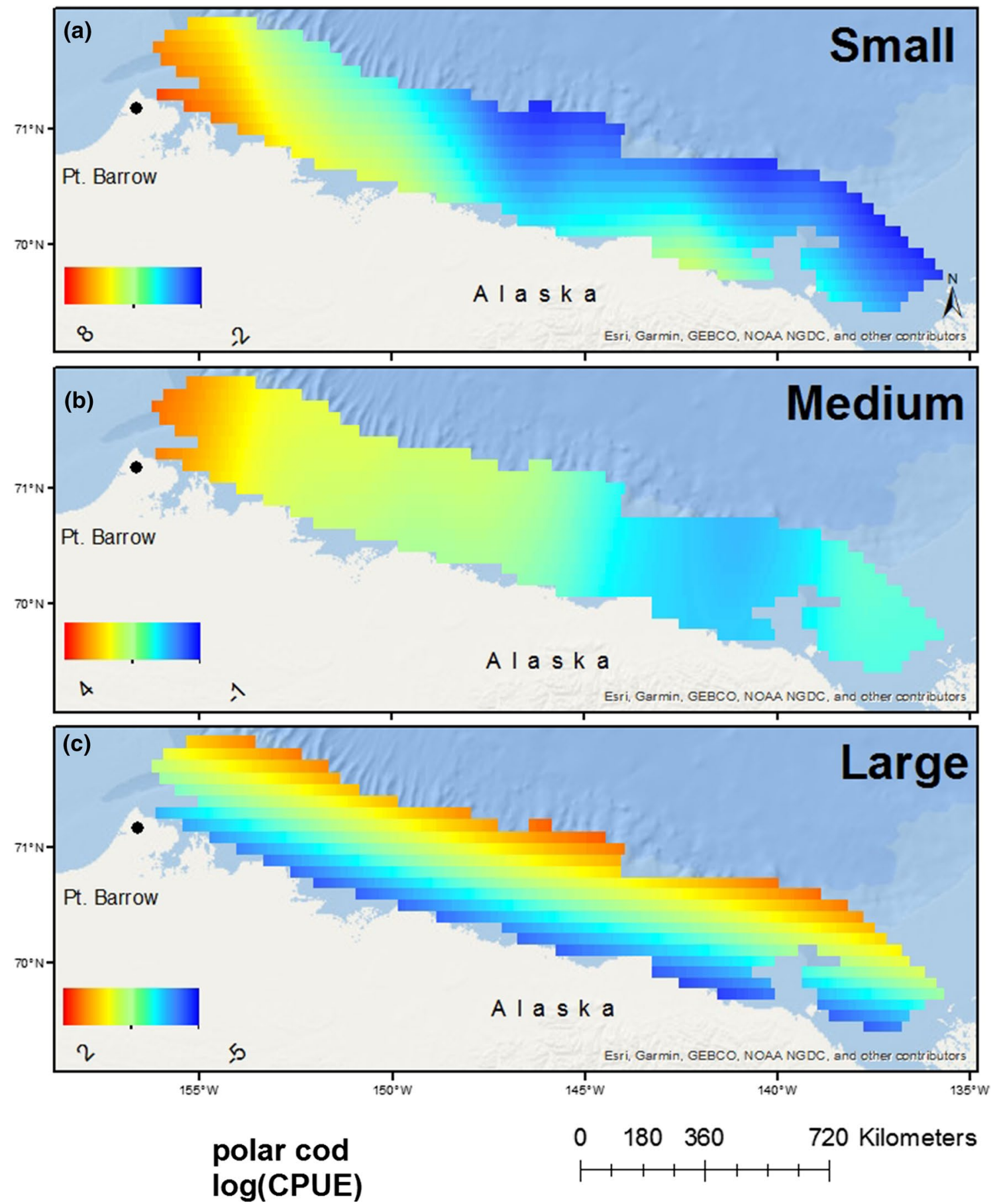

Fig. 5 Spatial distribution of polar cod catch per unit effort (CPUE, no. of fish per $\left.1000 \mathrm{~m}^{2}\right)$ in the Beaufort Sea for a small $(\leq 70 \mathrm{~mm})$, b medium $(71-130 \mathrm{~mm})$, and c large $(>130 \mathrm{~mm})$ size classes. Abun-

cod abundance. Finally, we hypothesize that both ontogenetic and seasonal movements of polar cod described in this study are evidence of a migration scenario that may be used to explain polar cod movement patterns in the Pacific Arctic. dances as predicted by generalized additive model (GAM) using a smooth function of latitude and longitude, shown on log scale

There are several assumptions implicit in this analysis that could impact the interpretation of polar cod distribution patterns and potential environmental drivers of those patterns. First, we assume that our sampling gear is reasonably 
Table 3 Results of generalized additive models (GAMs) in the Chukchi Sea for environmental covariates, depth, temperature, and salinity (see Eq. 2)

\begin{tabular}{|c|c|c|c|c|c|c|c|}
\hline Size class & $\begin{array}{l}s \text { (depth) } \\
(13-90 \mathrm{~m})\end{array}$ & $\begin{array}{l}s \text { (bottom } \\
\text { temperature) } \\
(-1.8 \text { to } \\
\left.10.9^{\circ} \mathrm{C}\right)\end{array}$ & $\begin{array}{l}\text { s (bottom } \\
\text { salinity) } \\
(27.2-34.5 \\
\text { PSU) }\end{array}$ & - (logLikelihood) & AIC & $\Delta \mathrm{AIC}$ & Model rank \\
\hline \multirow[t]{7}{*}{ Small } & & + & + & -1011.1 & 2034.1 & 0.0 & 1 \\
\hline & + & + & + & -1014.2 & 2044.3 & 10.2 & 2 \\
\hline & & + & & -1032.7 & 2073.5 & 39.3 & 3 \\
\hline & + & + & & -1054.5 & 2121.1 & 86.9 & 4 \\
\hline & & & + & -1075.7 & 2159.5 & 125.4 & 5 \\
\hline & + & & + & -1081.5 & 2174.9 & 140.8 & 6 \\
\hline & + & & & -1115.9 & 2239.8 & 205.7 & 7 \\
\hline \multirow[t]{7}{*}{ Medium } & + & & & -908.0 & 1824.0 & 0.0 & 1 \\
\hline & & & + & -919.7 & 1847.3 & 23.4 & 2 \\
\hline & + & & + & -919.7 & 1851.3 & 27.3 & 3 \\
\hline & & + & + & -920.6 & 1853.1 & 29.1 & 4 \\
\hline & + & + & + & -920.2 & 1856.5 & 32.5 & 5 \\
\hline & + & + & & -927.8 & 1867.6 & 43.6 & 6 \\
\hline & & + & & -933.0 & 1874.0 & 50.0 & 7 \\
\hline \multirow[t]{7}{*}{ Large } & + & & & -1224.2 & 2456.4 & 0.0 & 1 \\
\hline & + & + & & -1223.7 & 2459.5 & 3.1 & 2 \\
\hline & + & & + & -1247.0 & 2506.0 & 49.6 & 3 \\
\hline & + & + & + & -1312.7 & 2641.4 & 185.0 & 4 \\
\hline & & & + & -1477.5 & 2962.9 & 506.5 & 5 \\
\hline & & + & + & -1574.3 & 3160.6 & 704.2 & 6 \\
\hline & & + & & -1595.1 & 3198.2 & 741.8 & 7 \\
\hline
\end{tabular}

Suite of models developed for each polar cod size class, + denotes variables included in each model. The following statistics are reported: $-\log$ (likelihood), AIC, $\Delta$ AIC. Model performance ranked from best (1) to worst (7) using $\triangle \mathrm{AIC}$. $\Delta$ AIC calculated as the difference from the lowest AIC value for a size class and sea. $\theta$ parameter estimated independently and fixed, $\theta=0.345$. Inclusion of a spatially autocorrelated error structure precludes the calculation of $\%$ deviance explained effective at capturing all size classes of available polar cod. The $4 \mathrm{~mm}$ mesh codend liner ensures that this is an accurate assumption for individuals $<150 \mathrm{~mm}$; however, a gear selectivity study indicates that the PSBT may not be the most effective sampling gear for polar cod $>150 \mathrm{~mm}$ (Kotwicki et al. 2017). Despite this selectivity, the results presented here nevertheless capture the bulk of the polar cod length distribution, as similar studies deploying a net with higher selectivity for large fish found that the majority of polar cod catch was $<150 \mathrm{~mm}$ in both the Chukchi Sea (Goddard et al. 2016) and the Beaufort Sea (Rand and Logerwell 2011). Second, we assume that the negative binomial distribution is effective at accommodating both the non-normal distribution of abundance and the high proportion of zero catches in the data. Sensitivity analysis comparing the performance of other distribution families (i.e., normal distribution with log-transformed response and tweedie distribution) showed that the top performing model used a negative binomial distribution. Nevertheless, interpretation of analyses for the large size class should be undertaken cautiously, as there is a high proportion of zero-catch hauls for large fish. Patterns in abundance by size class (Online Resource 3) may be compared to GAM analysis output. Finally, by pooling data across years, we assume that the spatial patterns in average fish abundance are not biased by interannual variability in catches. In addition, the environmental analysis is limited in scope to local variables that were measured contemporaneously with at-sea sampling. Additional variables that may be correlated to polar cod distribution, such as mean sea ice coverage or mean distance to sea ice edge in the winter, were ultimately excluded, as we considered it inappropriate to relate the summer distribution of polar cod from multiple cruises conducted at different points in space and time to long-term means of winter sea ice conditions. However, it is important to consider that variable ice conditions during winter and spring likely also play a role in explaining 
Fig. 6 Estimated effects of three environmental variables on $\log$ (CPUE) of three size classes of polar cod in the Chukchi Sea based on generalized additive model (GAM) analysis; $y$-axis is magnitude of effect, rug along $x$-axis marks data values, colored envelopes are $95 \%$ confidence intervals. Results from the best model (Table 3 ) are displayed, and variables excluded from the best model are marked with N.I. (not included). Temperature and salinity measured at the seafloor. Characteristic water mass temperature and salinity values overlaid (BCSW Bering Chukchi Summer Water, $A C W$ Alaska Coastal Water)

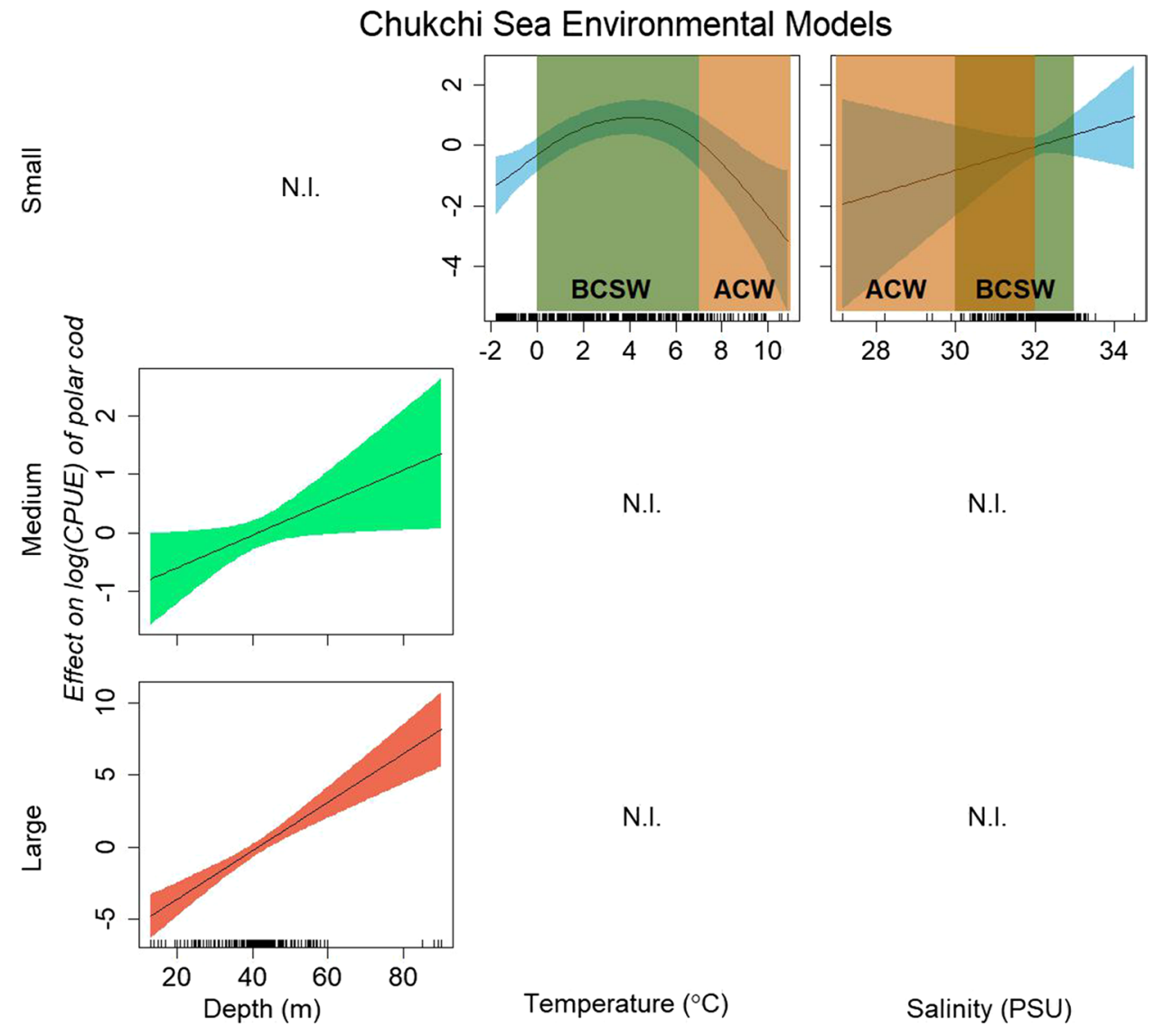

the distribution patterns of polar cod during the following summer.

\section{Spatial analysis}

In the Chukchi Sea, visualizing the distribution of the small size class of polar cod suggests oceanic transport of the juvenile life stage of this species. Due to small body size and weak swimming ability, the distribution of small individuals, such as the $\leq 70 \mathrm{~mm}$ polar cod considered here, is largely influenced by the direction and speed of the prevailing oceanic currents and sea ice drift (Graham and Hop 1995; David et al. 2016). Because age- 0 polar cod descend in the water column throughout their first summer (Geoffroy et al. 2016), the small polar cod captured in the demersal trawl had likely descended to the seafloor recently, after being subjected to movement by pelagic ocean currents. Pelagic acoustic surveys in the Chukchi Sea have also detected large numbers of small, 30-40 mm, age- 0 polar cod in the water column in the northern Chukchi Sea (De Robertis et al. 2017a, b), which supports the idea that young-of-the-year polar cod hatch in the spring and are advected from hatch locations via ocean currents.

The primarily northward flow of water through the Bering Strait and across the Chukchi Sea (Weingartner et al.
2013) suggests that the abundance of age- 0 polar cod found in the northeast Chukchi Sea in the late summer could have been transported from spawning locations in the southern Chukchi and northern Bering seas in Bering Shelf Water (BSW) and Anadyr Water (AW). Generally, polar cod hatch from buoyant eggs, occupy the water column as larvae, and descend to a demersal environment as they grow (Graham and Hop 1995; Ponomarenko 2000). Though still an area of active research, potential spawning grounds for polar cod in the Pacific Arctic have been proposed near St. Lawrence Island and east of the Chukotka peninsula, Russia (Ponomarenko 1968; Christiansen and Fevolden 2000; Vestfals et al. 2018), and could be the source of age- 0 polar cod transported northward and captured in the northeast Chukchi Sea in late summer. However, the detection of larvae throughout the Canadian Arctic (Bouchard and Fortier 2011) indicates that spawning grounds in the Bering and Chukchi seas may be only a few of several spawning regions throughout the Pacific range of polar cod.

As a result of the orientation of the Alaskan coastline, the distribution patterns in the Beaufort Sea of small polar cod display a primarily west to east gradient, coupled secondarily with an inshore to offshore gradient. As in the Chukchi Sea, however, the distribution of small individuals in the Beaufort Sea is likely largely influenced by oceanic currents. 
Table 4 Results of generalized additive models (GAMs) in the Beaufort Sea for environmental covariates, depth, temperature, and salinity (see Eq. 2)

\begin{tabular}{|c|c|c|c|c|c|c|c|}
\hline Size class & $\begin{array}{l}s \text { (depth) } \\
(9-987 \mathrm{~m})\end{array}$ & $\begin{array}{l}s \text { (bottom } \\
\text { temperature) } \\
(-1.6 \text { to } \\
\left.4.8^{\circ} \mathrm{C}\right)\end{array}$ & $\begin{array}{l}s \text { (bottom } \\
\text { salinity) } \\
(29.2-34.9 \\
\text { PSU) }\end{array}$ & - (logLikelihood) & AIC & $\Delta \mathrm{AIC}$ & Model rank \\
\hline \multirow[t]{7}{*}{ Small } & & + & + & -620.5 & 1252.9 & 0.0 & 1 \\
\hline & + & + & + & -594.8 & 1257.2 & 4.3 & 2 \\
\hline & + & + & & -700.6 & 1413.1 & 160.2 & 3 \\
\hline & + & & + & -754.5 & 1521.0 & 268.1 & 4 \\
\hline & & & + & -756.7 & 1521.3 & 268.4 & 5 \\
\hline & & + & & -767.4 & 1542.8 & 289.8 & 6 \\
\hline & + & & & -780.7 & 1569.5 & 316.6 & 7 \\
\hline \multirow[t]{7}{*}{ Medium } & + & + & & -501.4 & 1014.7 & 0.0 & 1 \\
\hline & + & + & + & -503.0 & 1022.0 & 7.3 & 2 \\
\hline & & + & & -543.7 & 1095.5 & 80.7 & 3 \\
\hline & & + & + & -552.3 & 1116.6 & 101.8 & 4 \\
\hline & + & & & -620.7 & 1249.3 & 234.6 & 5 \\
\hline & & & + & -629.8 & 1267.6 & 252.9 & 6 \\
\hline & + & & + & -633.1 & 1278.2 & 263.5 & 7 \\
\hline \multirow[t]{7}{*}{ Large } & + & & & -721.4 & 1450.9 & 0.0 & 1 \\
\hline & + & + & & -724.0 & 1460.0 & 9.1 & 2 \\
\hline & & + & & -740.2 & 1488.4 & 37.5 & 3 \\
\hline & + & & + & -764.1 & 1540.3 & 89.4 & 4 \\
\hline & & & + & -767.8 & 1543.6 & 92.7 & 5 \\
\hline & + & + & + & -766.8 & 1549.5 & 98.6 & 6 \\
\hline & & + & + & -775.7 & 1563.4 & 112.5 & 7 \\
\hline
\end{tabular}

Suite of models developed for each polar cod size class, + denotes variables included in each model. The following statistics are reported: $-\log$ (likelihood), AIC, $\Delta$ AIC. Model performance ranked from best (1) to worst (7) using $\triangle \mathrm{AIC}$. $\Delta$ AIC calculated as the difference from the lowest AIC value for a size class and sea. $\theta$ parameter estimated independently and fixed, $\theta=0.878$. Inclusion of a spatially autocorrelated error structure precludes the calculation of $\%$ deviance explained
A component of the Alaska Coastal Current (ACC), which may play a role in transporting polar cod northward in the Chukchi Sea, continues to flow along the Alaskan Coast, around Point Barrow, and into the Beaufort Sea (Okkonen et al. 2009). Barrow Canyon in the northern Chukchi Sea facilitates the movement of the ACC towards the Beaufort Sea (Pickart et al. 2005) and could effectively transport larval polar cod into the western Beaufort Sea as it does for zooplankton and other small particles (Ashjian et al. 2005; Berline et al. 2008). Further, small polar cod were also detected in the ACC in a plume extending $300 \mathrm{~km}$ eastward of Barrow Canyon (Crawford et al. 2012), demonstrating that small fish may be transported into the Beaufort Sea via eastward flowing currents.

Eastern and western aggregations of small polar cod in the Beaufort Sea, separated by a gap from $150^{\circ} \mathrm{W}$ to $144^{\circ}$ $\mathrm{W}$, suggests two separate groupings and perhaps distinct populations. Despite the prevailing eastward flow of water, the spatial separation indicates that polar cod in the eastern Beaufort Sea did not originate in the Chukchi Sea. Larval, juvenile, and adult polar cod are commonly captured in the
Canadian Beaufort Sea (Bouchard and Fortier 2011; Geoffroy et al. 2011; Walkusz et al. 2013) and could be a source of small polar cod in the eastern US Beaufort Sea. In 2011, pelagic, larval polar cod were most abundant in the eastern US Beaufort Sea when compared to the western US Beaufort Sea (Gallaway et al. 2017), suggesting that some polar cod in the US Beaufort Sea originate from Canadian sources. The distribution patterns are corroborated by a population genetic study which found that while polar cod comprises a single population, a significant difference in microsatellite alleles between polar cod from the southern Chukchi Sea and the central Beaufort Sea implies some degree of spatial genetic differentiation consistent with an isolation-by-distance pattern (Wilson et al. 2017, 2019). The low abundance of small polar cod between $150^{\circ} \mathrm{W}$ and $144^{\circ} \mathrm{W}$ is not an artifact of sparse sampling effort in the middle section, as the station sampling density is similar across the entire Beaufort Sea shelf; nor is it the result of a single year of low polar cod abundance, as this region was sampled over multiple years. Together, spatial and genetic information indicate that small polar cod across the Beaufort Sea shelf belong 
Fig. 7 Estimated effects of three environmental variables on $\log$ (CPUE) of three size classes of polar cod in the Beaufort Sea based on generalized additive model (GAM) analysis; $y$-axis is magnitude of effect, rug along $x$-axis mark location of data values, and colored envelopes are $95 \%$ confidence intervals. Results from the best model (Table 4) are displayed, and variables excluded from the best model are marked with N.I. (not included). Temperature and salinity measured at the seafloor. Characteristic water mass temperature and salinity values overlaid (SSW Summer Shelf Water, $A C W$ Alaska Coastal Water)

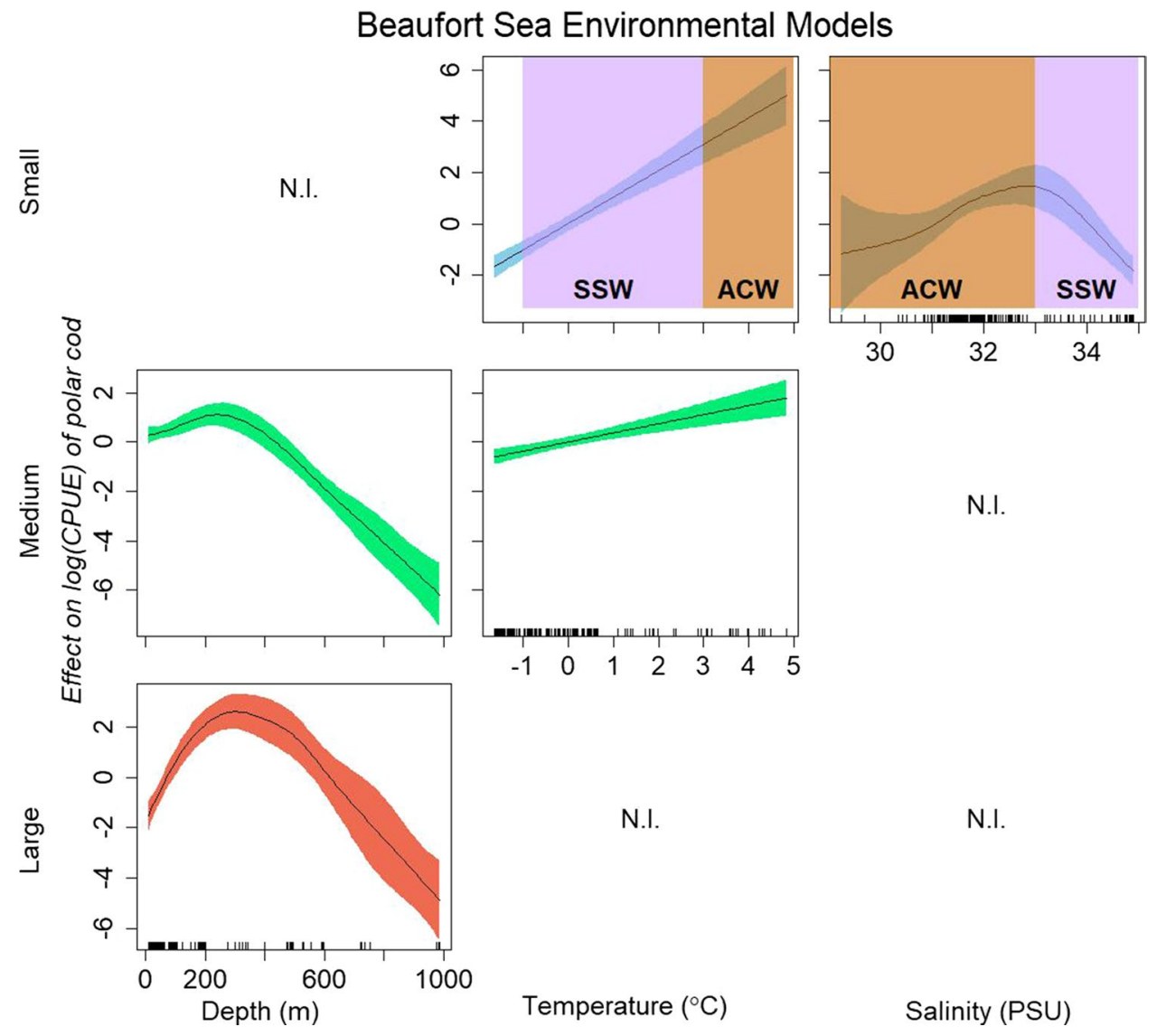

\begin{tabular}{lllllll}
\hline Season & Station $(n)$ & Depth & Temperature & Salinity & Size class & CPUE \\
\hline Spring & 9 & $43.1(9.69)$ & $1.69(1.22)$ & $32.42(0.39)$ & All & $0.71(1.11)$ \\
& & & & & $>70 \mathrm{~mm}$ & $0.50(1.04)$ \\
Summer & \multirow{2}{*}{14} & $39.1(13)$ & $4.18(0.95)$ & $32.26(0.56)$ & All & $70.31(219.92)$ \\
& & & & & $>70 \mathrm{~mm}$ & $3.02(3.52)$ \\
\hline
\end{tabular}

Mean and (standard deviation) environmental conditions reported for depth $(\mathrm{m})$, temperature $\left({ }^{\circ} \mathrm{C}\right)$, salinity (PSU). Mean and (standard deviation) CPUE reported for all polar cod as well as only polar cod $>70 \mathrm{~mm}$. CPUE significantly different $(p<0.05)$ between spring and summer for polar cod $>70 \mathrm{~mm}$ to two spatially segregated groups from different spawning locations.

In both the Chukchi and Beaufort seas, distribution patterns of medium and large polar cod suggest that larger fish actively disperse from areas occupied by the smallest fish. The small size class had a region of high abundance in the northeast Chukchi Sea that was not seen in the medium or large size classes. As fish develop, swimming ability improves (Webb 1994) and juveniles may disperse from nursery grounds to adult habitats (Gillanders et al. 2003). Improved dispersal capabilities gained with increasing body size could explain the spread of the medium size class beyond the confines of the areas occupied by small polar cod in the Chukchi and Beaufort seas. The large size class showed further evidence of offshore ontogenetic movement in both the Chukchi and Beaufort seas, where large polar cod were most abundant beginning around $80 \mathrm{~km}$ in the Chukchi Sea and $60 \mathrm{~km}$ in the Beaufort Sea and extending seaward. Animals are often distributed with respect to resource availability to maximize fitness and reduce competition (Fretwell and Lucas 1969). The northeast Chukchi Sea and western Beaufort Sea, where there were regions of high abundance of the medium size class, are areas of high summer production (Walsh et al. 2005; Sigler et al. 2011). Therefore, midsized individuals may be maximizing growth by dispersing to productive feeding grounds. Offshore movement of large polar cod may be a component of adult spawning migrations. In the Chukchi Sea, several spawning grounds have been 

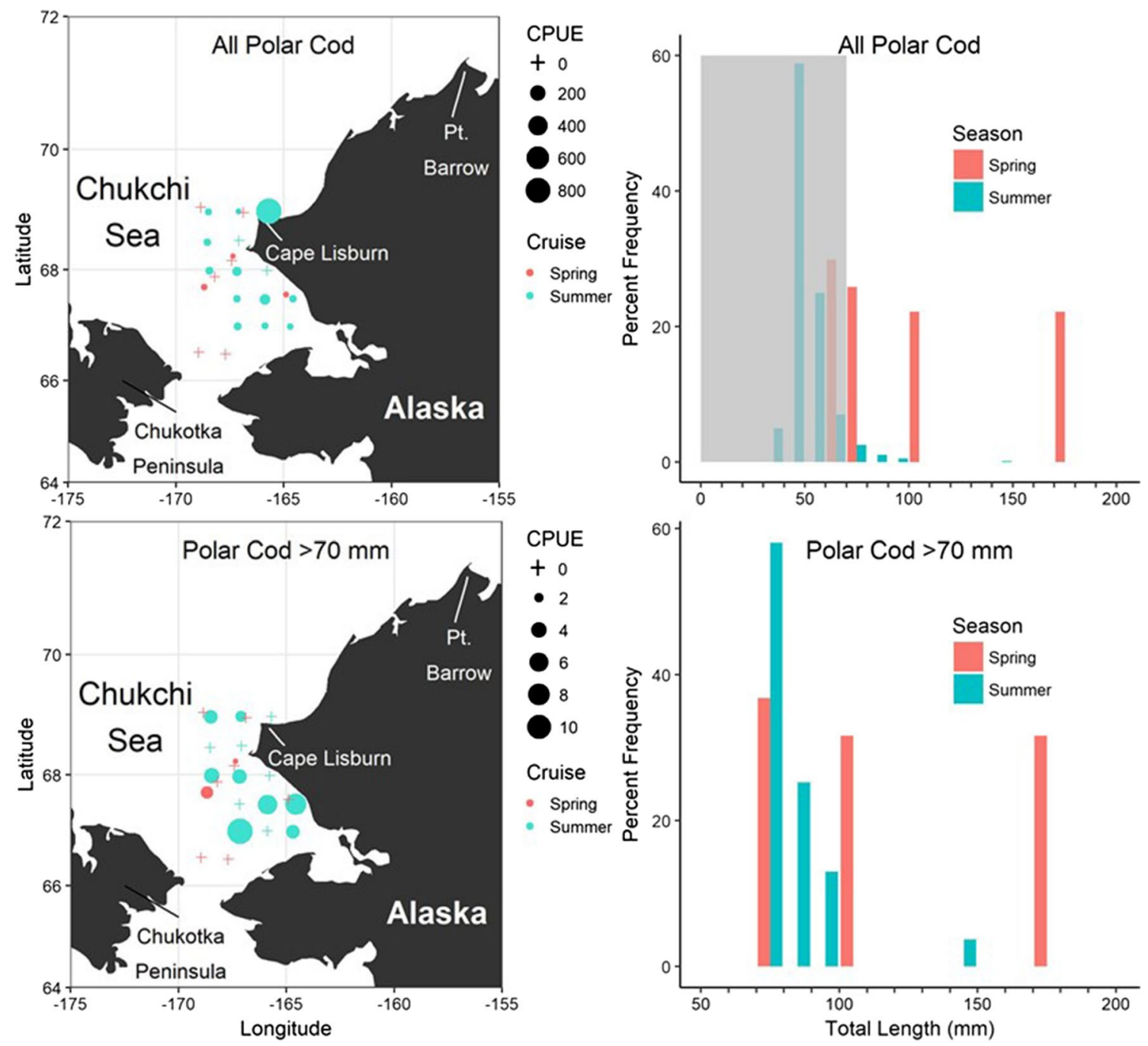

Fig. 8 Distribution and length-frequency of polar cod in the Chukchi Sea in spring and summer 2017. Length-frequency scaled by CPUE. Top two panels are all captured sizes of polar cod, total CPUE (fish per $1000 \mathrm{~m}^{2}$ ) spring $=6.43$, summer $=984.40$. Bottom two panels are

only polar $\operatorname{cod}>70 \mathrm{~mm}$, total CPUE spring $=4.51$, summer $=42.29$; gray box in top right shows small fish excluded from lower two plots. Note difference in scale between top left and bottom left plot

proposed in the northern Bering Sea and near the Chukotka peninsula (Ponomarenko 1968; Christiansen and Fevolden 2000; Vestfals et al. 2018). The abundance of the large size class of polar cod, both offshore and south of Cape Lisburne in the late summer, could reflect a movement towards these southern winter spawning locations.

\section{Environmental analysis}

Generally, both availability of food resources and temperature influence habitat selection of ectothermic species (Crowder and Magnuson 1983). Food resources are distributed unevenly among water masses (Eisner et al. 2013; Pinchuk and Eisner 2017; Smoot and Hopcroft 2017; Danielson et al. 2017b), which are identified by characteristic temperature and salinity ranges in the Chukchi and Beaufort seas. Temperature also has a direct physiological effect on growth rates of juvenile polar cod (Laurel et al. 2017) and likely influences their distribution. Depth commonly influences distribution patterns and is associated with offshore migrations of other species such as Pacific cod and Pacific halibut (Hippoglossus stenolepis), in the neighboring Bering Sea (Shimada and Kimura 1994; Webster et al. 2013). In Alaskan waters, the addition of environmental information to species distribution maps has been identified as a recent research objective in the Alaska Essential Fish Habitat Research Plan, which is mandated by the MagnusonStevens Fishery Conservation and Management Act (Sigler et al. 2017). Characterizing the role of environmental conditions for polar cod at different life stages moves towards this 
goal and identifies underlying processes influencing spatial patterns in distribution.

In the Chukchi Sea, small polar cod were associated with the intermediate temperature and salinity of the highly productive Bering Chukchi Summer Water (BCSW) mass. BCSW is a commonly detected water mass throughout the northeast Chukchi Sea during the open water season, with temperatures ranging from 0 to $7{ }^{\circ} \mathrm{C}$ and salinity from 30 to 33.5 PSU (Danielson et al. 2017b), which were the temperature and salinity ranges most commonly occupied by small polar cod (Fig. 6). Other water masses in the Chukchi Sea include the cooler Bering Chukchi Winter Water (BCWW) with temperatures from -2 to $0{ }^{\circ} \mathrm{C}$ and salinity from 30 to $33 \mathrm{PSU}$, and the warmer Alaska Coastal Water (ACW) with temperatures from 7 to $12{ }^{\circ} \mathrm{C}$ and salinity from 27 to $32 \mathrm{PSU}$ (Danielson et al. 2017b); however, small polar cod were less abundant in these water masses. BCSW is a nutrient-rich water mass with a characteristic zooplankton community of calanoid copepods and euphausiids (Eisner et al. 2013), which are prey for polar cod (Rand et al. 2013; Gray et al. 2016). In contrast, the BCWW and ACW are less nutrient rich, and have smaller-bodied zooplankton communities, including species such as Oithona similis, Calanus abdominalis, and Pseudocalanus spp. (Eisner et al. 2013), which are marginal resources when compared to lipid-rich Calanus copepods (Falk-Petersen et al. 2009). Maximizing energy intake as a result of consuming high-quality prey resources is beneficial to polar cod and results in increased growth rates and improved body condition (Hop et al. 1997). Therefore, distribution patterns of small polar cod in the Chukchi Sea are likely influenced by the abundance and composition of prey resources in different water masses.

In the Beaufort Sea, small polar cod were primarily associated with relatively warm and moderately fresh water found near the Alaskan coast. Environmental conditions in the Beaufort Sea are markedly different from those found in the Chukchi Sea; the warmest sampled Beaufort Sea temperature of $5{ }^{\circ} \mathrm{C}$ is comparable to the intermediate temperatures found in the Chukchi Sea. Yet in both the Chukchi and Beaufort seas (Figs. 6, 7), small polar cod were most abundant in water temperatures $4-5{ }^{\circ} \mathrm{C}$. However, the relationship between small polar cod abundance and salinity differed between the Chukchi and Beaufort seas. Unlike in the Chukchi Sea where abundance increased linearly with salinity to a maximum of 34.5 PSU, small polar cod in the Beaufort Sea were less abundant at salinities $>34$ PSU. Cold and saline water is associated with Summer Shelf Water (SSW), and our results suggest that the differing effect of salinity between seas is likely due to this association of small polar cod with distinct water masses, characterized by a signature combination of temperature and salinity (Danielson et al. 2017b).
The warm and fresh water occupied by small polar cod in the Beaufort Sea is associated with nearshore coastal habitats and the eastward flowing ACW (Okkonen et al. 2009; Carmack et al. 2015), and could impact growth of individuals in the small size class. This warm coastal water is not nutrient rich (Dunton et al. 2005), but does provide a thermal habitat that is advantageous for polar cod. Though polar cod is a cold-adapted species and capable of surviving in sub-zero temperatures (Osuga and Feeney 1978), it is more commonly found at temperatures above $0{ }^{\circ} \mathrm{C}$ (Crawford et al. 2012). Small polar cod in the Beaufort Sea appear to be occupying the warmest available water to maximize growth. Higher growth rates are advantageous for the small, age0, individuals (Helser et al. 2017). In harsh Arctic winters, survivorship increases dramatically when pre-winter size and body condition are good (Fortier et al. 2006; Heintz and Vollenweider 2010), while large gape size and increased swimming speeds enable better resource exploitation (Scharf et al. 2000). In the Beaufort Sea, the thermal advantages of warm, coastal water appear to be correlated with patterns of distribution of small polar cod. Though warm coastal water may be advantageous for growth in certain scenarios, the cost of occupying low nutrient and low production waters could result in a tradeoff with negative energetic consequences, including a scenario where accelerated growth outstrips resource availability, impacting polar cod growth and survival in the Beaufort Sea.

The positive relationship between depth and abundance (Figs. 6, 7) indicates that depth is a key environmental component correlated with the offshore shift in distribution of the medium and large size classes of polar cod in the Chukchi and Beaufort seas. In the Chukchi Sea, where sampled depths were 13-90 m, the increasing linear relationship with depth suggests that polar cod moves to offshore, somewhat deeper locations as they grow larger. In the Beaufort Sea, where sampled depths reached nearly $1000 \mathrm{~m}$, medium and large polar cod were most abundant at 300 and $400 \mathrm{~m}$, respectively, demonstrating that as individuals increase in size, they move offshore to a specific bottom depth range. A nearly identical pattern was identified in the Canadian Beaufort, where medium and large fish $(\sim 90+\mathrm{mm})$ were encountered at deep, offshore stations and the highest abundances of those fish were found at depths between 350 and $500 \mathrm{~m}$ (Geoffroy et al. 2011; Benoit et al. 2014; Majewski et al. 2016). The distribution pattern of polar cod was attributed to distinctly layered water masses in the Canadian Beaufort Sea (Pickart 2004), with polar cod occupying a layer of Atlantic Water, which was warmer than $0{ }^{\circ} \mathrm{C}$ and detected from 350 to $500 \mathrm{~m}$ depth. In the present study area, Atlantic Water was observed in the US Beaufort Sea at depths $>250 \mathrm{~m}$ (Norcross et al. 2017; Smoot and Hopcroft 2017), and this was where large polar cod were most abundant (Fig. 7). 
Therefore, polar cod occupies the Atlantic Water mass in both the US and Canadian Beaufort Sea.

\section{Seasonal analysis}

Springtime demersal abundance of polar cod in the southern Chukchi Sea was strikingly low compared to late summer abundance. Low springtime abundance of demersal polar cod during 2017, when only four fish were captured, was corroborated the following year when a June 2018 research cruise captured only two polar cod at the same sampling locations (Danielson et al. 2018). While adult polar cod were not present in the demersal environment in the southern Chukchi Sea in the spring, small polar cod $(<20 \mathrm{~mm})$ were captured in Bongo nets (R. Hopcroft, personal communication) concurrently sampled with the bottom trawl in June 2017 and 2018. The bottom trawl gear used in June 2017 and 2018 was identical to the gear used in the late summer collections that successfully captured demersal polar cod in the same region. Though there were approximately half the number of stations sampled in June when compared to August, the stations were distributed across the study area to maximize spatial sampling extent (Fig. 8). It is likely that growth of age- 0 polar cod between June and August/September resulted in a higher catch of age- 0 polar cod in the late summer. However, the complete lack of larger $(>70 \mathrm{~mm})$, older (age $1+$ ) individuals, which would be equally susceptible to the net in June and August/September suggests that the collections in June likely truly represent a lower abundance of subadult and adult polar cod near the sea floor in the southern Chukchi Sea in the spring.

Strong linkages between sea ice and polar cod life history suggest that the distribution of polar cod in the southern Chukchi Sea could be influenced by the distribution of sea ice. While polar cod occupies environments that are seasonally ice free, it is often characterized as a sympagic species for a portion of its life cycle (Craig et al. 1982; Lønne and Gulliksen 1989). Polar cod is thought to spawn under sea ice, and buoyant eggs float to the ice-water interface before hatching in early spring (Graham and Hop 1995; Bouchard and Fortier 2011). Sea ice also provides a platform for the growth of sea ice algae, which is not only an important source of primary productivity in the Arctic, but also has a distinct isotopic signature that can be traced throughout Arctic food webs (Iken et al. 2005; Gradinger 2009). Isotopic and fatty acid analyses have linked polar cod to seaice-derived carbon, demonstrating the significant influence that sea ice can have on the diet of polar cod (Kohlbach et al. 2017; Dissen et al. 2018). Finally, the seasonal melting of sea ice is a driver of springtime patterns of productivity in the Arctic, with ice-edge blooms typically following the retreat of sea ice, resulting in peak productivity $\sim 20$ days after ice retreat (Perrette et al. 2011). The spring bloom stimulates and supports secondary productivity, ultimately resulting in planktonic food resources for polar cod (Sigler et al. 2011; Wassmann and Reigstad 2011).

Given the link between sea ice and polar cod life history, sea ice extent and retreat may influence the spring distribution of polar cod in the southern Chukchi Sea. It is possible that polar cod tracks the springtime ice retreat and the wave of productivity that follows. However, in the springs of both 2017 and 2018, when sampling occurred, the sea ice edge had already retreated far north of the sampling region (NASA 2018). If polar cod followed the ice edge in these years, then its distribution would be beyond the northernmost station sampled during the June cruises, explaining the extremely low abundances of subadult and adult polar cod observed in the southern Chukchi Sea. It is unlikely that the low abundances of subadult and adult polar cod in the southern Chukchi Sea can be explained by polar cod moving south into the northern Bering Sea. Though polar cod is found episodically in the northern Bering Sea in association with cold conditions and large ice extent (Wyllie-Echeverria and Wooster 1998; Cui et al. 2009), these conditions did not occur in 2017 or 2018. Furthermore, sampling in the northern Bering Sea from St. Lawrence Island to the Bering Strait caught few polar cod in 2017 and 2018 (Danielson et al. 2018), suggesting that polar cod did not move into the northern Bering Sea.

Movement inferred from size-based and seasonal patterns in distribution describes a plausible migration scenario. In classical fisheries science, the life history of a species that undertakes a migration triangle travels from nursery grounds as juveniles, to feeding grounds as subadults, to spawning grounds upon maturation. The triangle is complete when eggs and larvae are passively transported from the spawning grounds to the nursery grounds via oceanic currents and the cycle begins again (Harden Jones 1968; Secor 2002). Small, young polar cod are most abundant in the northeast Chukchi Sea, perhaps indicating that region functions as nursery grounds for juveniles. The northeast Chukchi Sea was also proposed as a nursery area by researchers analyzing the pelagic distribution of age- 0 polar cod, though the suggestion remains untested (De Robertis et al. 2017b). The next step in a migration triangle is the movement of subadults to feeding grounds; in the current study, the distribution pattern of the medium size class was different from the small size class, indicating that medium polar cod move away from areas occupied by small fish and disperse across the productive northeast Chukchi Sea shelf (Grebmeier 2012) to take advantage of feeding opportunities. The final component of a classic migration triangle is movement to spawning grounds; the current study cannot address this directly as polar cod spawns in the late fall and early winter under sea ice (Ponomarenko 2000). Several locations in the northern Bering 
Sea and near the Chukotka peninsula have been recognized for their potential as polar cod spawning grounds (Ponomarenko 1968; Christiansen and Fevolden 2000; Vestfals et al. 2018); and are geographically close to the late summer distribution of the large size class in this study, which contains the majority of the mature spawners (Nahrgang et al. 2016). Potential spawners in the southern Chukchi Sea in late summer would not have far to travel to proposed spawning grounds during the fall and winter seasons.

Completion of the proposed migration scenario could be achieved via advection of eggs and larvae by the northbound currents traveling through Bering Strait and across the Chukchi Sea (Weingartner et al. 2005). Pelagic (De Robertis et al. 2017b) and demersal distributions are consistent with northward advection of eggs and larvae from southern spawning grounds. The spring absence of polar cod from the southern Chukchi Sea may be explained within the framework of the proposed migration triangle. In the spring, adult polar cod following the seasonal northward retreat of sea ice may be spawners seeking resources to replenish their depleted energy reserves. Spawning is energetically costly and these individuals would likely need to take advantage of the earliest available food resources (Hop et al. 1995). This possible movement scenario synthesizes both size-based and seasonal distribution patterns of polar cod and represents a new effort to characterize polar cod migration patterns in the Chukchi Sea.

The migration of a small-bodied, high-latitude fish species is not unprecedented, but there remains much uncertainty surrounding the migration patterns of polar cod in the Chukchi Sea. Other marine fish species, such as Pacific herring and walleye pollock in the Bering Sea, exhibit seasonal migrations between feeding grounds and spawning grounds (Kotwicki et al. 2005; Tojo et al. 2007). Additionally, telemetry studies in the Atlantic Arctic found that polar cod is physically capable of traveling over $100 \mathrm{~km}$ in response to rapidly evolving ice conditions (Kessel et al. 2015). The migration triangle proposed here is currently constrained by data collected during open water sampling efforts. Moored acoustics offer an opportunity to confirm and refine understanding of polar cod movement during the Arctic winter and are currently being deployed in the Chukchi and Beaufort seas (Kitamura et al. 2017; Hauri et al. 2018). Patterns in backscatter collected at moorings during the ice-covered season provide information on fish presence and abundance when net sampling is not possible (Kaartvedt et al. 2009). In addition to increased field sampling efforts, modeling studies using tools like ROMS will corroborate the direction and timing of transport of polar cod eggs and larvae in ocean currents, improving understanding of polar cod movement throughout their life cycle in the Chukchi Sea. The scale of detail of the migration triangle proposed here is coarse and based on a small sample size, but nevertheless provides an initial framework against which new information may be tested to advance understanding of polar cod movement patterns in the Chukchi Sea.

\section{Conclusions}

Advancing fisheries science in the remote and difficult to access Arctic ecosystem is a significant research challenge. The work presented here compiles a large number of disparate individual sampling efforts to develop a holistic picture describing polar cod summer distribution in the Chukchi and Beaufort seas. The size-based analysis demonstrates ontogenetic shifts in distribution, while consideration of environmental covariates provides insight into potential mechanisms driving these patterns. Though much work remains to be done in understanding polar cod distribution and migration, the comparison between spring and summer abundances shows that polar cod distribution in the Pacific Arctic varies by season and suggests that this species may undertake some form of seasonal migration. The mapping of polar cod distribution in the Chukchi and Beaufort seas improves understanding of one of the most abundant and critical trophic links in the Arctic ecosystem. As the Arctic experiences increased anthropogenic and climatological pressures, thorough knowledge of key components of this system, including species like polar cod, will inform responsible decision making in this dynamic and rapidly changing ecosystem.

Acknowledgements We thank reviewers Kevin Hedges, Wojciech Walkusz, and Hauke Flores for their insightful and constructive review of this manuscript. We thank the scientists, research vessels' captains and crew who collected the data compiled in this study. We also thank past and present members of the UAF Fisheries Oceanography lab for their laboratory work processing specimens. Funds were provided by the North Slope Borough and the Arctic Integrated Research Program sponsored by the North Pacific Research Board (NPRB). In addition, this study was funded in part by material sampled under Award Numbers M10AC0004, M12AC00011, and M13PC00019 of the U.S. Department of the Interior, Bureau of Ocean Energy Management (BOEM), Alaska Outer Continental Shelf Region. In-kind support was contributed by the National Oceanic and Atmospheric Administration (Alaska Fisheries Science Center) and the University of Alaska Fairbanks. This paper represents NPRB publication ArcticIERP-15.

Conflict of interest The authors declare that they have no conflicts of interest.

Ethical approval All applicable national and international guidelines for the care and use of animals were followed. Sample collections in US waters were approved by the Institutional Animal Care and Use Committee (IACUC) of the University of Alaska Fairbanks. 


\section{References}

Abookire AA, Rose CS (2005) Modifications to a plumb staff beam trawl for sampling uneven, complex habitats. Fish Res 71:247254. https://doi.org/10.1016/j.fishres.2004.06.006

Ashjian CJ, Gallager SM, Plourde S (2005) Transport of plankton and particles between the Chukchi and Beaufort Seas during summer 2002, described using a Video Plankton Recorder. Deep Sea Res Part II 52:3259-3280. https://doi.org/10.1016/j.dsr2.2005.10.012

Astthorsson OS (2015) Distribution, abundance and biology of polar cod, Boreogadus saida, in Iceland-East Greenland waters. Polar Biol 39:995-1003. https://doi.org/10.1007/s00300-015-1753-5

Benaglia T, Chauveau D, Hunter DR (2009) An EM-like algorithm for semi-and nonparametric estimation in multivariate mixtures. $\mathrm{J}$ Comput Graph Stat 18:505-526

Benoit D, Simard Y, Fortier L (2008) Hydroacoustic detection of large winter aggregations of Arctic cod (Boreogadus saida) at depth in ice-covered Franklin Bay (Beaufort Sea). J Geophys Res 113:19. https://doi.org/10.1029/2007jc004276

Benoit D, Simard Y, Fortier L (2014) Pre-winter distribution and habitat characteristics of polar cod (Boreogadus saida) in southeastern Beaufort Sea. Polar Biol 37:149-163. https://doi. org/10.1007/s00300-013-1419-0

Berline L, Spitz YH, Ashjian CJ, Campbell RG, Maslowski W, Moore SE (2008) Euphausiid transport in the Western Arctic Ocean. Mar Ecol Prog Ser 360:163-178. https://doi.org/10.3354/meps0 7387

Bouchard C, Fortier L (2011) Circum-arctic comparison of the hatching season of polar cod Boreogadus saida: A test of the freshwater winter refuge hypothesis. Prog Oceanogr 90:105-116. https ://doi.org/10.1016/j.pocean.2011.02.008

Carmack EC, Macdonald RW (2002) Oceanography of the Canadian shelf of the Beaufort Sea: a setting for marine life. Arctic 55:S29-S45

Carmack EC, Macdonald RW, Papadakis JE (1989) Water mass structure and boundaries in the Mackenzie shelf estuary. J Geophys Res 94:18043-18055. https://doi.org/10.1029/JC094 iC12p18043

Carmack E, Winsor P, Williams W (2015) The contiguous panarctic Riverine Coastal Domain: a unifying concept. Prog Oceanogr 139:13-23. https://doi.org/10.1016/j.pocean.2015.07.014

Christensen B (1996) Predator foraging capabilities and prey antipredator behaviours: pre-versus postcapture constraints on sizedependent predator-prey interactions. Oikos 96:368-380

Christiansen JS, Fevolden S-E (2000) The polar cod of Porsangerfjorden, Norway; revisited. Sarsia 85:89-193. https://doi. org/10.1080/00364827.2000.10414571

Clark DL, Leis JM, Hay AC, Trnski T (2005) Swimming ontogeny of larvae of four temperate marine fishes. Mar Ecol Prog Ser 292:287-300

Craig P, Griffiths W, Haldorson L, McElderry H (1982) Ecological Studies of Arctic Cod (Boreogadus saida) in Beaufort Sea Coastal Waters, Alaska. Can J Fish Aquat Sci 39:395-406

Crawford RE, Vagle S, Carmack EC (2012) Water mass and bathymetric characteristics of polar cod habitat along the continental shelf and slope of the Beaufort and Chukchi seas. Polar Biol 35:179-190. https://doi.org/10.1007/s00300-011-1051-9

Crowder LB, Magnuson JJ (1983) Cost-benefit analysis of temperature and food resource use: a synthesis with examples from the fishes. In: Aspey WP, Lustick SI (eds) Behavioral energetics. Ohio State University Press, Columbus, pp 189-221

Cui X, Grebmeier JM, Cooper LW, Lovvorn JR, North CA, Seaver WL, Kolts JM (2009) Spatial distributions of groundfish in the northern Bering Sea in relation to environmental variation. Mar Ecol Prog Ser 393:147-160. https://doi.org/10.3354/meps08275
Danielson S, Ahkinga O, Edenfield L, Eisner L, Forster C, Hardy S, Hartz S, Holladay B, Hopcroft R, Jones B, Krause J, Kuletz K, Lekanoff R, Lomas M, Lu K, Norcross B, O’Daly S, Pretty J, Pham C, Poje A, Roth E, Seabrook S, Shipton P, Smith B, Smoot C, Stafford K, Stockwell D, Yamaguchi A, Zinkann A (2017a) Arctic Shelf Growth, Advection, Respiration and Deposition (ASGARD) rate measurements project. Anchorage AK: North Pacific Research Board. SKQ201709S Cruise Report to the Arctic Integrated Research Program

Danielson SL, Eisner L, Ladd C, Mordy C, Sousa L, Weingartner TJ (2017b) A comparison between late summer 2012 and 2013 water masses, macronutrients, and phytoplankton standing crops in the northern Bering and Chukchi Seas. Deep Sea Res Part II 135:7-26. https://doi.org/10.1016/j.dsr2.2016.05.024

Danielson S, Ahkinga O, Baer S, Chapman Z, Collins E, Edenfeld L, Escajeda E, Forster C, Gonzalez S, Hardy S, Hopcroft R, Iken K, Jones B, Juranek L, Kuletz K, Lomas M, Naber D, Norcross B, McDonnell A, Mendoza H, O'Daly S, Poje A, Roth E, Shipton P, Smith B, Smoot C, Stafford K, Stockwell D, Thurber A (2018) Arctic Shelf Growth, Advection, Respiration and Deposition (ASGARD) Rate Measurements Project. Anchorage AK: North Pacific Research Board. SKQ201813 Cruise Report to the Arctic Integrated Research Program

David C, Lange B, Krumpen T, Schaafsma F, van Franeker JA, Flores $\mathrm{H}$ (2016) Under-ice distribution of polar cod Boreogadus saida in the central Arctic Ocean and their association with sea-ice habitat properties. Polar Biol 39:981-994. https://doi.org/10.1007/s0030 0-015-1774-0

De Robertis A, Taylor K, Williams K, Wilson CD (2017a) Species and size selectivity of two midwater trawls used in an acoustic survey of the Alaska Arctic. Deep Sea Res Part II 135:40-50. https:// doi.org/10.1016/j.dsr2.2015.11.014

De Robertis A, Taylor K, Wilson CD, Farley EV (2017b) Abundance and distribution of Arctic cod (Boreogadus saida) and other pelagic fishes over the U.S. Continental Shelf of the Northern Bering and Chukchi Seas. Deep Sea Res Part II 135:51-65. https://doi.org/10.1016/j.dsr2.2016.03.002

Dissen JN, Oliveira AC, Horstmann L, Hardy SM (2018) Regional and temporal variation in fatty acid profiles of polar cod (Boreogadus saida) in Alaska. Polar Biol 41:2495-2510

Dunton KH, Goodall JL, Schonberg SV, Grebmeier JM, Maidment DR (2005) Multi-decadal synthesis of benthic-pelagic coupling in the western arctic: Role of cross-shelf advective processes. Deep Sea Res Part II 52:3462-3477. https://doi. org/10.1016/j.dsr2.2005.09.007

Eisner L, Hillgrubber N, Martinson E, Maselko J (2013) Pelagic fish and zooplankton species assemblages in relation to water mass characteristics in the northern Bering and southeast Chukchi seas. Polar Biol 36:87-113

Falk-Petersen S, Mayzaud P, Kattner G, Sargent JR (2009) Lipids and life strategy of Arctic Calanus. Mar Biol Res 5:18-39

Fortier L, Sirois P, Michaud J, Barber D (2006) Survival of Arctic Cod larvae (Boreogadus saida) in relation to sea ice and temperature in the Northeast Water Polynya (Greenland Sea). Can J Fish Aquat Sci 63:1608-1616

Fretwell SD, Lucas HL (1969) On territorial behavior and other factors influencing habitat distribution in birds. Acta Biotheor $19: 16-36$

Gallaway BJ, Konkel WJ, Norcross BL (2017) Some thoughts on estimating change to arctic cod populations from hypothetical oil spills in the Eastern Alaska Beaufort Sea. Arct Sci 3:716729. https://doi.org/10.1139/as-2016-0056

Geoffroy M, Robert D, Darnis G, Fortier L (2011) The aggregation of polar cod (Boreogadus saida) in the deep Atlantic layer of icecovered Amundsen Gulf (Beaufort Sea) in winter. Polar Biol 34:1959-1971. https://doi.org/10.1007/s00300-011-1019-9 
Geoffroy M, Majewski A, LeBlanc M, Gauthier S, Walkusz W, Reist JD, Fortier L (2016) Vertical segregation of age-0 and age$1+$ polar cod (Boreogadus saida) over the annual cycle in the Canadian Beaufort Sea. Polar Biol 39:1023-1037. https://doi. org/10.1007/s00300-015-1811-z

Gillanders BM, Able KW, Brown JA, Eggleston DB, Sheridan PF (2003) Evidence of connectivity between juvenile and adult habitats for mobile marine fauna: an important component of nurseries. Mar Ecol Prog Ser 247:281-295

Goddard P, Lauth R, Armistead C (2016) Results of the 2012 Chukchi Sea bottom trawl survey of bottomfishes, crabs, and other demersal macrofauna. Juneau AK: US Dept. of the Interior, Bureau of Ocean Management, Alaska OCS Region. Report for BOEM agreement Numbers M12AC00009 (UAF), M12PG00018 (AFSC) and M10PG00050 (USF\&WS)

Gradinger R (2009) Sea-ice algae: major contributors to primary production and algal biomass in the Chukchi and Beaufort Seas during May/June 2002. Deep Sea Res Part II 56:1201-1212. https://doi.org/10.1016/j.dsr2.2008.10.016

Graham M, Hop H (1995) Aspects of reproduction and larval biology of Arctic Cod (Boredogadus saida). Arctic 48:130-135

Gray BP, Norcross BL, Blanchard AL, Beaudreau AH, Seitz AC (2016) Variability in the summer diets of juvenile polar cod (Boreogadus saida) in the northeastern Chukchi and western Beaufort Seas. Polar Biol 39:1069-1080. https://doi. org/10.1007/s00300-015-1796-7

Gray BP, Norcross BL, Beaudreau AH, Blanchard AL, Seitz AC (2017) Food habits of Arctic staghorn sculpin (Gymnocanthus tricuspis) and shorthorn sculpin (Myoxocephalus scorpius) in the northeastern Chukchi and western Beaufort Seas. Deep Sea Res Part II 135:111-123. https://doi.org/10.1016/j. dsr2.2016.05.013

Grebmeier JM (2012) Shifting patterns of life in the Pacific Arctic and sub-Arctic seas. Ann Rev Marine Sci 4:63-78. https://doi. org/10.1146/annurev-marine-120710-100926

Grebmeier JM, McRoy CP, Feder HM (1988) Pelagic-benthic coupling on the shelf of the northern Bering and Chukchi seas. 1. Food supply source and benthic biomass. Mar Ecol Prog Ser 48:57-67

Grebmeier JM, Cooper LW, Feder HM, Sirenko BI (2006) Ecosystem dynamics of the Pacific-influenced Northern Bering and Chukchi Seas in the Amerasian Arctic. Prog Oceanogr 71:331-361. https ://doi.org/10.1016/j.pocean.2006.10.001

Gunderson DR, Ellis IE (1986) Development of a plumb staff beam trawl for sampling demersal fauna. Fish Res 4:35-41

Harden Jones FR (1968) Fish migration. Edward Arnold, London

Hastie TJ, Tibshirani RJ (1986) Generalized additive models. Statistical Science 1:297-318

Hauri C, Danielson S, McDonnell AMP, Hopcroft RR, Winsor P, Shipton P, Lalande C, Stafford KM, Horne JK, Cooper LW, Grebmeier JM, Mahoney A, Maisch K, McCammon M, Statscewich H, Sybrandy A, Weingartner T (2018) From sea ice to seals: a moored marine ecosystem observatory in the Arctic. Ocean Sci 14:1423-1433

Heintz RA, Vollenweider JJ (2010) Influence of size on the sources of energy consumed by overwintering walleye pollock (Theragra chalcogramma). J Exp Mar Biol Ecol 393:43-50. https://doi. org/10.1016/j.jembe.2010.06.030

Helser TE, Colman JR, Anderl DM, Kastelle CR (2017) Growth dynamics of saffron cod (Eleginus gracilis) and Arctic cod (Boreogadus saida) in the Northern Bering and Chukchi Seas. Deep Sea Res Part II 135:66-77. https://doi.org/10.1016/j. dsr2.2015.12.009

Hop H, Gjosaeter H (2013) Polar cod (Boreogadus saida) and capelin (Mallotus villosus) as key species in marine food webs of the Arctic and the Barents Sea. Marine Biol Res 9:878-894. https:// doi.org/10.1080/17451000.2013.775458
Hop H, Trudeau VL, Graham M (1995) Spawning energetics of Arctic cod (Boreogadus saida) in relation to seasonal development of the ovary and plasma sex steroid levels. Can J Fish Aquat Sci 52:541-550. https://doi.org/10.1139/f95-055

Hop H, Tonn WM, Welch HE (1997) Bioenergetics of Arctic cod (Boreogadus saida) at low temperatures. Can J Fish Aquat Sci 54:1772-1784

Iken K, Bluhm BA, Gradinger R (2005) Food web structure in the high Arctic Canada Basin: evidence from 13C and $15 \mathrm{~N}$ analysis. Polar Biol 28:238-249. https://doi.org/10.1007/s00300-004-0669-2

Kaartvedt S, Røstad A, Klevjer TA, Staby A (2009) Use of bottommounted echo sounders in exploring behavior of mesopelagic fishes. Mar Ecol Prog Ser 395:109-118. https://doi.org/10.3354/ meps08174

Kahru M, Brotas V, Manzano-Sarabia M, Mitchell BG (2011) Are phytoplankton blooms occurring earlier in the Arctic? Glob Change Biol 17:1733-1739. https://doi.org/10.111 1/j.1365-2486.2010.02312.x

Kessel ST, Hussey NE, Crawford RE, Yurkowski DJ, O'Neill CV, Fisk AT (2015) Distinct patterns of Arctic cod (Boreogadus saida) presence and absence in a shallow high Arctic embayment, revealed across open-water and ice-covered periods through acoustic telemetry. Polar Biol 39:1057-1068. https:// doi.org/10.1007/s00300-015-1723-y

Kitamura M, Amakasub K, Kikuchia T, Nishinoa S (2017) Seasonal dynamics of zooplankton in the southern Chukchi Sea revealed from acoustic backscattering strength. Cont Shelf Res 133:47-58

Kohlbach D, Schaafsma FL, Graeve M, Lebreton B, Lange BA, David C, Vortkamp M, Flores H (2017) Strong linkage of polar cod (Boreogadus saida) to sea ice algae-produced carbon: evidence from stomach content, fatty acid and stable isotope analyses. Prog Oceanogr. https://doi.org/10.1016/j.pocean.2017.02.003

Kotwicki S, Buckley TW, Honkalehto T, Walters G (2005) Variation in the distribution of walleye pollock (Theragra chalcogramma) with temperature and implications for seasonal migration. Fish Bull 103:574-587

Kotwicki S, Lauth RR, Williams K, Goodman SE (2017) Selectivity ratio: a useful tool for comparing size selectivity of multiple survey gears. Fish Res 191:76-86. https://doi.org/10.1016/j.fishr es.2017.02.012

Lansard B, Mucci A, Miller LA, Macdonald RW, Gratton Y (2012) Seasonal variability of water mass distribution in the southeastern Beaufort Sea determined by total alkalinity and $\delta 180$. J Geophys Res 117:1-19. https://doi.org/10.1029/2011jc007299

Laurel BJ, Copeman LA, Spencer M, Iseri P (2017) Temperaturedependent growth as a function of size and age in juvenile Arctic cod (Boreogadus saida). ICES J Mar Sci 74:1614-1621. https:// doi.org/10.1093/icesjms/fsx028

Logerwell E, Busby M, Carothers C, Cotton S, Duffy-Anderson J, Farley E, Goddard P, Heintz R, Holladay B, Horne J, Johnson S, Lauth B, Moulton L, Neff D, Norcross B, Parker-Stetter S, Seigle J, Sformo T (2015) Fish communities across a spectrum of habitats in the western Beaufort Sea and Chukchi Sea. Prog Oceanogr 136:115-132. https://doi.org/10.1016/j.pocean.2015.05.013

Logerwell E, Rand K, Danielson S, Sousa L (2017) Environmental drivers of benthic fish distribution in and around Barrow Canyon in the northeastern Chukchi Sea and western Beaufort Sea. Deep Sea Res Part II 152:170-181. https://doi.org/10.1016/j. dsr2.2017.04.012

Lønne OJ, Gulliksen B (1989) Size, age and diet of polar cod, Boreogadus saida (Lepechin 1773), in ice covered waters. Polar Biol 9:187-191. https://doi.org/10.1007/bf00297174

Lowry LF, Frost KJ (1981) Distribution, Growth, and Foods of Arctic Cod (Boreogadus saida) in the Bering, Chukchi, and Beaufort Seas. Can Field Nat 95:186-191 
Majewski AR, Walkusz W, Lynn BR, Atchison S, Eert J, Reist JD (2016) Distribution and diet of demersal Arctic Cod, Boreogadus saida, in relation to habitat characteristics in the Canadian Beaufort Sea. Polar Biol 39:1087-1098. https://doi.org/10.1007/ s00300-015-1857-y

Mecklenburg CW, Møller PR, Steinke D (2011) Biodiversity of arctic marine fishes: taxonomy and zoogeography. Marine Biodivers 41:109-140

Mueter FJ, Nahrgang J, John Nelson R, Berge J (2016) The ecology of gadid fishes in the circumpolar Arctic with a special emphasis on the polar cod (Boreogadus saida). Polar Biol 39:961-967. https ://doi.org/10.1007/s00300-016-1965-3

Nahrgang J, Storhaug E, Murzina SA, Delmas O, Nemova NN, Berge J (2016) Aspects of reproductive biology of wild-caught polar cod (Boreogadus saida) from Svalbard waters. Polar Biol 39:11551164. https://doi.org/10.1007/s00300-015-1837-2

NASA (2018) Sea ice index: data and image archive. https://nsidc.org/ data/seaice_index/archives.

Nichol DG (1998) Annual and between-sex variability of yellowfin sole, Pleuronectes asper, spring-summer distributions in the eastern Bering Sea. Fish Bull 96:547-561

Norcross BL, Holladay BA, Busby MS, Mier KL (2010) Demersal and larval fish assemblages in the Chukchi Sea. Deep Sea Res Part II 57:57-70. https://doi.org/10.1016/j.dsr2.2009.08.006

Norcross BL, Raborn SW, Holladay BA, Gallaway BJ, Crawford ST, Priest JT, Edenfield LE, Meyer R (2013) Northeastern Chukchi Sea demersal fishes and associated environmental characteristics, 2009-2010. Cont Shelf Res 67:77-95. https://doi.org/10.1016/j. csr.2013.05.010

Norcross BL, Apsens SJ, Bell LE, Bluhm BA, Dissen JN, Edenfield LE, Frothingham A, Gray BP, Hardy SM, Holladay BA, Hopcroft RR, Iken KB, Smoot CA, Walker KL, Wood ED (2017) US-Canada transboundary fish and lower trophic communities: abundance, distribution, habitat and community analysis. Fairbanks AK: US Dept. of the Interior, Bureau of Ocean Energy Management, Alaska OCS Region. Final Report for BOEM Agreement Number M12AC00011

Norcross BL, Holladay BA, Apsens SJ, Edenfield LE, Gray BP, Walker KL (2018) Central Beaufort Sea marine fish monitoring. Fairbanks AK: US Department of the Interior, Bureau of Ocean Energy Management, Final Report for OCS Study BOEM 2017-33

NPFMC (2009) Fishery management plan for fish resources of the arctic management area. North Pacific Fisheries Management Council, Anchorage

Okkonen SR, Ashjian CJ, Campbell RG, Maslowski W, Clement-Kinney JL, Potter R (2009) Intrusion of warm Bering/Chukchi waters onto the shelf in the western Beaufort Sea. J Geophys Res 114:1-23. https://doi.org/10.1029/2008jc004870

Osuga DT, Feeney RE (1978) Antifreeze glycoprotiens from arctic fish. J Biol Chem 253:5338-5343

Perrette M, Yool A, Quartly GD, Popova EE (2011) Near-ubiquity of ice-edge blooms in the Arctic. Biogeosciences 8:515-524. https:// doi.org/10.5194/bg-8-515-2011

Pickart RS (2004) Shelfbreak circulation in the Alaskan Beaufort Sea: mean structure and variability. J Geophys Res 109:1-14. https:// doi.org/10.1029/2003jc001912

Pickart RS, Weingartner TJ, Pratt LJ, Zimmermann S, Torres DJ (2005) Flow of winter-transformed Pacific water into the Western Arctic. Deep Sea Res Part II 52:3175-3198. https://doi.org/10.1016/j. dsr2.2005.10.009

Pinchuk AI, Eisner LB (2017) Spatial heterogeneity in zooplankton summer distribution in the eastern Chukchi Sea in 2012-2013 as a result of large-scale interactions of water masses. Deep Sea Res Part II 135:27-39. https://doi.org/10.1016/j.dsr2.2016.11.003

Ponomarenko V (1968) Some data on the distribution and migrations of polar cod in the seas of the Soviet Arctic. Rapports et Proces-verbaux des Réunions Conseil International pour l'Éxploration de la Mer 158:131-135

Ponomarenko V (2000) Eggs, larvae, and juveniles of polar cod Boreogadus saida in the Barents, Kara, and White Seas. J Ichthyol 40:165-173

R Core Team (2017) R: a language and environment for statistical computing. R Foundation for Statistical Computing, Vienna

Rand KM, Logerwell EA (2011) The first demersal trawl survey of benthic fish and invertebrates in the Beaufort Sea since the late 1970s. Polar Biol 34:475-488. https://doi.org/10.1007/s00300-010-0900-2

Rand KM, Whitehouse A, Logerwell EA, Ahgeak E, Hibpshman R, Parker-Stetter S (2013) The diets of polar cod (Boreogadus saida) from August 2008 in the US Beaufort Sea. Polar Biol 36:907-912. https://doi.org/10.1007/s00300-013-1303-y

Scharf FS, Juanes F, Rountree RA (2000) Predator size-prey size relationships of marine fish predators: interspecific variation and effects of ontogeny and body size on trophic-niche breadth. Mar Ecol Prog Ser 208:229-248

Secor DH (2002) Historical roots of the migration triangle. ICES Marine Sci Symp 2002:323-329

Shimada A, Kimura DK (1994) Seasonal movements of Pacific Cod, Gadus macrocephalus, in the eastern Bering Sea and adjacent waters based on tag-recapture data. Fish Bull 92:800-816

Sigler M, Renner M, Danielson S, Eisner L, Lauth R, Kuletz K, Logerwell E, Hunt G (2011) Fluxes, fins, and feathers: relationships among the Bering, Chukchi, and Beaufort seas in a time of climate change. Oceanography 24:250-265. https://doi.org/10.5670/ocean og.2011.77

Sigler M, Eagleton M, Helser T, Olson J, Pirtle J, Rooper C, Simpson S, Stone R (2017) Alaska essential fish habitat research plan: a research plan for the National Marine Fisheries Service's Alaska Fisheries Science Center and Alaska Regional Office. Juneau AK: NOAA, National Marine Fisheries Service, Alaska Fisheries Science Center. AFSC Processed Report 2015-05

Smoot CA, Hopcroft RR (2017) Depth-stratified community structure of Beaufort Sea slope zooplankton and its relations to water masses. J Plankton Res 39:79-91. https://doi.org/10.1093/plankt/fbw087

Tojo N, Kruse GH, Funk FC (2007) Migration dynamics of Pacific herring (Clupea pallasii) and response to spring environmental variability in the southeastern Bering Sea. Deep Sea Res Part II 54:2832-2848. https://doi.org/10.1016/j.dsr2.2007.07.032

Vestfals CD, Mueter FJ, Hedstrom KS, Laurel BJ, Petrik CM, DuffyAnderson JT, Danielson SL, De Robertis A, Curchitser EN (2018) Arctic gadids in a changing climate. Anchorage AK: North Pacific Research Board. Final report for NPRB Project Number 1508

Walkusz W, Majewski A, Reist JD (2013) Distribution and diet of the bottom dwelling Arctic cod in the Canadian Beaufort Sea. J Mar Syst 127:65-75. https://doi.org/10.1016/j.jmarsys.2012.04.004

Walsh JJ, Dieterle DA, Maslowski W, Grebmeier JM, Whitledge TE, Flint M, Sukhanova IN, Bates N, Cota GF, Stockwell D, Moran SB, Hansell DA, McRoy CP (2005) A numerical model of seasonal primary production within the Chukchi/Beaufort Seas. Deep Sea Res Part II 52:3541-3576. https://doi.org/10.1016/j.dsr2.2005.09.009

Wassmann P, Reigstad M (2011) Future Arctic Ocean seasonal ice zones and implications for pelagic-benthic coupling. Oceanography 24:220-231. https://doi.org/10.5670/oceanog.2011.74

Webb PW (1994) The biology of fish swimming. In: Maddock L, Bone Q, Rayner JM (eds) Mechanics and physiology of animal swimming. Cambridge University Press, Oxford, pp 45-62

Webster RA, Clark WG, Leaman BM, Forsberg JE, Hilborn R (2013) Pacific halibut on the move: a renewed understanding of adult migration from a coastwide tagging study. Can J Fish Aquat Sci 70:642-653. https://doi.org/10.1139/cjfas-2012-0371

Weingartner T (1997) A review of the physical oceanography of the northeastern Chukchi Sea. In: Fish ecology in Arctic North America. American Fisheries Society Symposium, pp 40-59 
Weingartner T, Aagaard K, Woodgate R, Danielson S, Sasaki Y, Cavalieri D (2005) Circulation on the north central Chukchi Sea shelf. Deep Sea Res Part II 52:3150-3174. https://doi.org/10.1016/j. dsr2.2005.10.015

Weingartner T, Dobbins E, Danielson S, Winsor P, Potter R, Statscewich H (2013) Hydrographic variability over the northeastern Chukchi Sea shelf in summer-fall 2008-2010. Cont Shelf Res 67:5-22. https ://doi.org/10.1016/j.csr.2013.03.012

Werner EE, Hall DJ (1974) Optimal foraging and the size selection of prey by the Bluegill sunfish (Lepomis macrochirus). Ecology 55:1042-1052

Wilson RE, K SG, Sonsthagen SA, Gravley MC, Menning DM, Talbot SL (2017) Genomics of arctic cod. Anchorage, AK: US Dept. of the Interior, Bureau of Ocean Energy Management, Alaska OCS Region. Report for BOEM OSC Study 2017-066

Wilson RE, Sage GK, Wedemeyer K, Sonsthagen SA, Menning DM, Gravely MC, Sexson MG, Nelson RJ, Talbot SL (2019)
Micro-geographic population genetic structure within Arctic cod (Boreogadus saida) in Beaufort Sea of Alaska. ICES J Mar Sci. https://doi.org/10.1093/icesjms/fsz041

Wood S (2006) Generalized additive models: an introduction with R Taylor and Francis Group, Boca Raton, FL

Wyllie-Echeverria T, Wooster WS (1998) Year-to-year variation in Bering Sea ice cover and some consequences for fish distributions. Fish Oceanogr 7:159-170

Zuur A, Ieno E, Smith G (2007) Analysing ecological data. Springer, New York

Publisher's Note Springer Nature remains neutral with regard to jurisdictional claims in published maps and institutional affiliations. 